\title{
Konzeption 4:
}

Ein Sklavenball mit Gesang und Tanz in drei Akten - Masken 
$\|$ EIN SKLAVENBALL

mit Gesang und Tanz in drei Akten von $\ulcorner$ Ödön $\urcorner$ von $\ulcorner$ Horváth?

ÖLA 3/W 109 BS 30 a, BI. 1

\section{|| PERSONEN}

5

K.R. Thago, ein punischer Bankier

Idiotima, seine Tochter

Gloriosus, deren Mann

Toxilus, Oberkammersklave

${ }_{10}\ulcorner$ Lemniselenis $\urcorner$, eine Hetäre

Matrosa, deren Dienerin

Der Aufseher

Paegnium, ein Sklavenlausbub

Bagnio, ein entlaufener Sklave

15

Der Praetor von Pompeji

Dordalus, Sklavenhändler

Sklaven und Sklavinnen.

\section{ZEIT}

Im Altertum. Innerhalb vierundzwanzig Stunden.

\section{|| SCHAUPLATZ}

25

Kleiner Privathafen vor einer Villa am Meer, unweit von Pompeji. Die Villa ist der ländliche Lustsitz des reichen punischen Bankiers K.R. Thago, eines naturalisierten Römers. Hier wohnt er im Frühling mit seiner Tochter Idiotima und derem Gatten Gloriosus.

30 Rechts im Vordergrunde sieht man einige Säulen der Villa, links im Hintergrunde liegt das Meer.

\section{$\|$ ERSTER AKT.}

35 Es beginnt mit einem $\ulcorner$ lebendem Bild:

$\ulcorner$ Im Hafen links im Hintergrunde, $\urcorner$ ankert die Luxusgaleere des Bankiers. ZAHLREICHE SKLAVEN schleppen vom \ulcorner\urcorner Ufer Gepäckstücke auf das Schiff, Kisten, Truhen, Fässer, Schläuche, Geschirr. Sie werden von einem AUfSEHER mit Nilpferdpeitsche in drohender Pose beaufsichtigt. Im Vordergrunde stehen von links nach rechts: GLORIOsus mit $\left\ulcorner\right.$ dem Sklavenlausbub PäGnium, ${ }^{\prime}\ulcorner$ der Gloriosus Schild putzt. $\urcorner$ Dann IDIotima, umgeben von zwei Kammersklavinnen, die am Boden knien und am Saum ihres

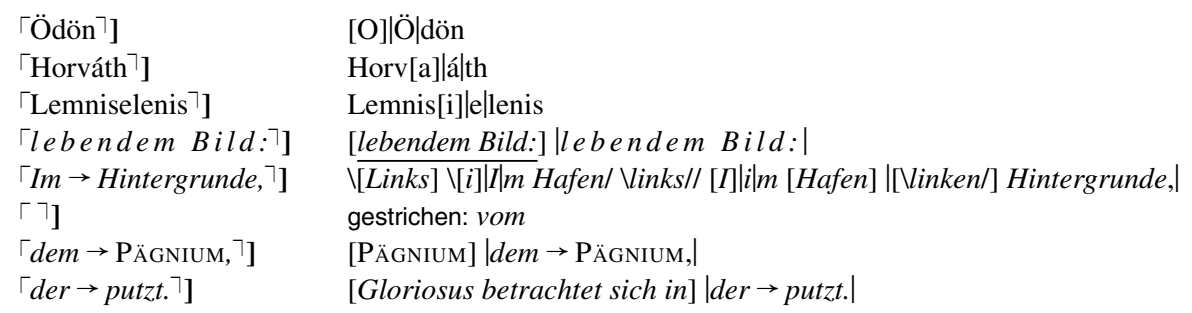


Kleides nähen und richten. Eine steht hinter ihr und richtet $\left\ulcorner\right.$ letzte Löckchen ${ }^{\urcorner}$ihrer Frisur. Dann: $\ulcorner$ K.R. THAGO $\urcorner$ persönlich $\urcorner$ mit $\ulcorner$ der achtzehnjährigen $\urcorner$ LEMNISELENIS und deren Dienerin Matrosa, einer $\ulcorner$ Person $\urcorner$ im gefährlichsten Alter. $\ulcorner$ K.R. Thago $\urcorner$ tätschelt Lemniselenis Wange oder: zählt Geld. Alle tragen griechische Masken vor ihrem $\ulcorner$ Gesicht, die ihre $\ulcorner$ Charakterzüge $\urcorner\ulcorner$ darstellen: $\urcorner$ Die Sklaven, bedrückt Aufseher, \ulcorner\urcorner dumm - stolze, Gloriosus eitel - dumm - aufgeblasen. 「PäGNium, $\ulcorner$ Lausbub $\urcorner\urcorner$, IDIOTImA, geschmerzt $-\ulcorner$ versnobbt, $\urcorner$ THAGO, $\ulcorner$ Börsianer, $\urcorner$ LeM (halb Kind $-\ulcorner\text { verdorben })^{\urcorner}$MATRosa (viel gesehen, $\ulcorner$alt und $\urcorner$leise verbittert) $\left.\urcorner\right\urcorner$

$\ulcorner$ Es ist ein herrlicher Tag ohne Wellen und Wolken.

10

$\ulcorner$ Toxilus (tritt aus der Villa -\ulcorner\urcorner ebenfalls mit Maske: $\ulcorner$ der Oberkammersklave, eine Herrennatur in „Persa“", $\ulcorner$ pfiffig -$\urcorner$ schlau - spitzbübisch - doch $\left\ulcorner\right.$ gutmütig $-{ }^{\urcorner}$er tritt an die Rampe; zum $\ulcorner$ Publikum) $\urcorner$

Als Prologus

$\ulcorner$ beginne $\urcorner$ ich mit einem Zitat aus Plautus:

$\left\ulcorner\right.$ „Oh ${ }^{\urcorner}$Publikum!

$\left\ulcorner\right.$ Lasst Euch ${ }^{\urcorner}$behaglich auf $\left\ulcorner\right.$Euere ${ }^{\urcorner}$Sessel nieder

Bezahlt oder unbezahlt - das ist \ulcorner\urcorner nicht die Frage.

Die Frage ist vielmehr: ob Ihr satt oder hungrig hierher gekommen seid.

$\left\ulcorner\right.$ Wer bereits genachtmahlt hat, der hat das bessere ${ }^{\ulcorner}$Teil erwählt.

\begin{tabular}{|c|c|c|}
\hline 1 & $\ulcorner$ letzte Löckchen $]$ & [ihre] |letzte Löckchen| \\
\hline 2 & $\ulcorner$ K.R. THAGO $\urcorner]$ & korrigiert aus: K. R. THAGO \\
\hline 2 & $\ulcorner$ persönlich $\rceil$ & persönlich/ \\
\hline 2 & $\lceil$ der achtzehnjährigen $\rceil]$ & Ider achtzehnjährigen/ \\
\hline 3 & $\ulcorner$ Person $\rceil$ & {$[$ Frau $] \mid$ Person $\mid$} \\
\hline 3 & $\ulcorner$ K.R. Thago $\urcorner]$ & korrigiert aus: K. R. Thago \\
\hline $5-8$ & $\ulcorner$ Gesicht $\rightarrow$ verbittert $)\urcorner]$ & Gesicht[.]],| \die $\rightarrow$ verbittert)/ \\
\hline 5 & $\ulcorner$ Charakterzüge $\rceil]$ & Charakter $[e] \mid z$ üge $\mid$ \\
\hline 5 & $\ulcorner$ darstellen: $\urcorner]$ & [übertreiben -] |darstellen:| \\
\hline 6 & \ulcorner\urcorner$]$ & {$[\mathrm{roh}-]$} \\
\hline $6-7$ & $\ulcorner$ PäGNIUM, Lausbub $\rceil]$ & |PäGNIUM, Lausbub/ \\
\hline 7 & $\ulcorner$ Lausbub, $\urcorner]$ & korrigiert aus: Lausbub \\
\hline 7 & $\ulcorner$ versnobbt, $\urcorner]$ & korrigiert aus: versnobbt \\
\hline 7 & $\ulcorner$ Börsianer, $\urcorner]$ & korrigiert aus: Börsianer \\
\hline 8 & $\lceil$ verdorben $)\rceil]$ & verdorben $[] \mid,) \mid[$ doch $]$ \\
\hline 8 & $\ulcorner$ alt und $\urcorner]$ & alt $[] \mid$, und $\mid$ \\
\hline 8 & $\ulcorner$ leise verbittert $)\rceil]$ & [gutmüt] $\mid$ leise verbittert || \\
\hline 9 & $\ulcorner$ Es $\rightarrow$ Wolken. $\urcorner]$ & Es $\rightarrow$ Wolken./ \\
\hline $11-322,5$ & $\ulcorner$ Toxilus $\rightarrow$ ist!“”] & Textentlehnung Plautus, $\mathrm{POE}^{1}$ \\
\hline 11 & \ulcorner\urcorner$]$ & {$[\backslash$ der $\rightarrow$ Persa“, /] $] \rightarrow \bullet$} \\
\hline $11-12$ & $\ulcorner$ der $\rightarrow$ Persa “" $\urcorner]$ & -der $\rightarrow$ Persa", \\
\hline 12 & 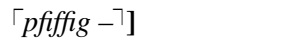 & pfiffig -/ \\
\hline 12 & $\lceil$ gutmütig -$\urcorner]$ & gutmütig[)] $|-|$ \\
\hline 13 & $\ulcorner$ Publikum $)\urcorner]$ & Publikum $[;] \mid) \mid[$ er nimmt die Maske ab] \\
\hline 15 & $\lceil$ beginne $\rceil]$ & {$[\mathrm{B}] \mid \mathrm{b}$ |eginne } \\
\hline 16 & $\ulcorner, \mathrm{Oh}\urcorner]$ & {$[,],|,,| \mathrm{Oh}$} \\
\hline 17 & $\ulcorner$ Lasst Euch $\rceil]$ & Lasslt/ [Dich] $\mid$ Euch $\mid$ \\
\hline 17 & $\ulcorner$ Euere $\urcorner]$ & [Deine] |Euere| \\
\hline 18 & \ulcorner\urcorner$]$ & [hier] \\
\hline 19 & \ulcorner\urcorner$]$ & [Setzt Euch nur hin -] \\
\hline $21-322,1$ & $\ulcorner$ Wer $\rightarrow$ satt -$\urcorner]$ & [Denn seid Ihr hungrig gekommen] $\mid$ Wer $\rightarrow$ satt - \\
\hline 21 & $\ulcorner$ Teil erwählt. $\urcorner]$ & Teil[.] lerwählt.| \\
\hline
\end{tabular}


$\left\ulcorner\right.$ Doch wer ${ }^{\urcorner}$hungert, esse sich an unseren Witzen satt -$\urcorner$

Aber wem zu Haus das Nachtmahl $\left\ulcorner\right.$ steht ${ }^{\urcorner}$

Der ist ein $\ulcorner$ Narr! $\urcorner$

Ein grosser $\ulcorner$ Narr -$\urcorner$

5 Dass er uns zulieb nüchtern hergekommen ist!‘7

(er nimmt die Maske ab)

$\mathrm{Hu}$, ist mir heiss!

Verzeiht, dass ich mich $\ulcorner$ demaskiere -$\urcorner$

Doch hoffe ich, dass Ihr mich auch ohne Maske $\ulcorner$ goutieren $\urcorner$ werdet:

10

Erlaubt, dass ich mich vorstelle:

Ich heisse Toxilus und bin hier der Oberkammersklave -

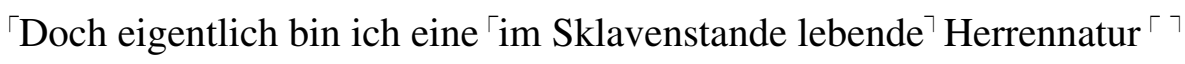

Ein Mann voll geistiger Kraft und Gewandtheit

Dem sich seine Umgebung völlig unterordnet -7

Die Sklaven nämlich, deren $\ulcorner$ Oberster $\urcorner$ ich bin -

$\ulcorner$ Jedoch $\urcorner$ auch -\ulcorner\urcorner

$\ulcorner$ (leise $)\urcorner$ meine ${ }^{\urcorner}$Herrschaft!

Ich sag es leise, denn sie steht hier und soll es nicht hören!

Sonst ${ }^{\ulcorner}$setzt $^{\urcorner}$es was ab $\ulcorner$auf meinen Buckel $\urcorner$und das wollt Ihr mir doch nicht gön-

20 nen!

$\ulcorner($ laut $)\urcorner$ Erlaubt $\ulcorner$ nun $\urcorner$, dass ich Euch die Szene erkläre:

Es ist ein lebendes Bild. ${ }^{r}$ Rechts $\urcorner\left\ulcorner\right.$ seht $\operatorname{Ihr}^{\urcorner}$die Villa meiner Herrschaft und links im

Hintergrunde das Meer und den Privathafen, in dem die Luxusgaleere ankert.

$\ulcorner$ Meine Herrschaft seht ihr $\urcorner$ im Vordergrunde, und $\left\ulcorner\right.$ zwar: ${ }^{\urcorner}$(er deutet auf THAGO)

Mein Herr \| K.R. Thago, der Präsident $\ulcorner$ des $\urcorner$ Römisch-phönizischen Kreditinstitutes $\urcorner$. Er ist ein Punier, hat sich aber in Rom naturalisieren lassen und $\ulcorner$ mit jedwedem Mittel ${ }^{\urcorner}$viel Geld gemacht. Seine Tochter Idiotima, $\ulcorner$mit Kammerskla-

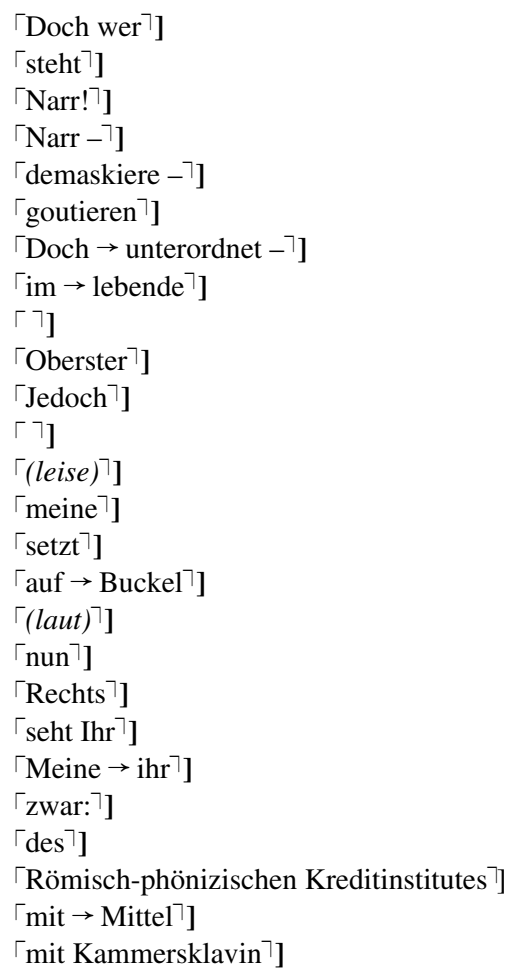

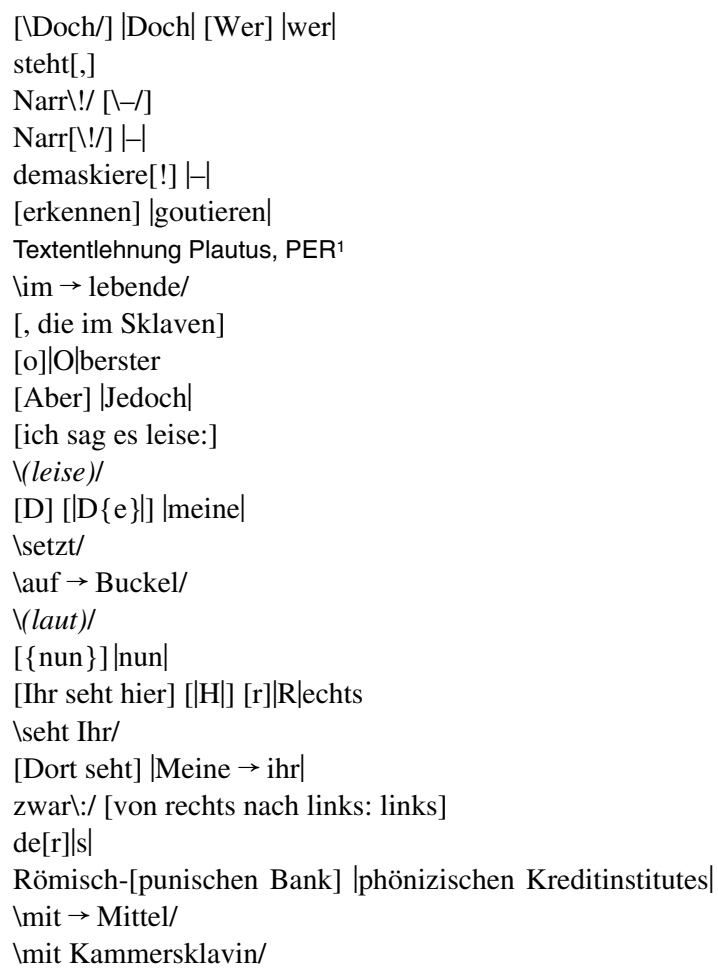


vin $\urcorner$ und deren Mann $\ulcorner$ Gloriosus, mit dem $\ulcorner$ Sklaven $\urcorner$ PäGNIUM, ein richtiger Lausbub, der seinen Schild putzt. $\urcorner$ Sie stehen hier und wollen die Galeere besteigen, um nach Kreta in die Sommerfrische zu fahren, denn Kreta ist zur Zeit der letzte Schrei. ${ }^{\urcorner}$Sie warten nur, bis die Sklaven dort das $\ulcorner$Gepäck $\urcorner$auf $\left\ulcorner\right.$die ${ }^{\ulcorner}$Luxusgaleere ${ }^{\urcorner}$bringen. Die SkLAVEn werden von einem Aufseher kontrolliert, der ${ }^{\ulcorner}$Rüpel ${ }^{\urcorner\urcorner}$dort mit der Peitsche, er ist ${ }^{\ulcorner}$selber nur ein Sklave, aber er ist der gediegenste Prügelwart und Peitschenkuli ${ }^{\urcorner}$ein unangenehmer, roher, \ulcorner\urcorner$\ulcorner\{$brutaler $\}\urcorner$ Bursche -

AufseHER (fällt ihm ins Wort) Was bin ich?!

10 Toxilus Du hat es ja gehört! Zweimal sag ichs nicht.

AufseHER Ich bin ein $\left\ulcorner\right.$ roher, brutaler ${ }^{\ulcorner}$Rüpel $\urcorner ? ! ?$

Toxilus Hab ich das gesagt?

Aufseher Ja!

Toxilus Dann wirds schon stimmen!

15 Aufseher Es stimmt nicht! Da schau her - (er nimmt die Maske ab, ein gutmütiges $\left\ulcorner\right.$ rundes ${ }^{\urcorner}$Gesicht $\{$leuchtet $\left.\}\right)$Ist das das $\ulcorner$Antlitz $\urcorner$eines Prügelwarts?!

Toxilus Ach, sieh da! Ich hab Dein Antlitz eigentlich noch nie gesehen - hm. Nein, \ulcorner\urcorner roh und brutal sieht es nicht aus, eher ein bisserl blöd -

Aufseher $\ulcorner$ Ein Wort noch, und Du kriegst die Peitsche!

20 Toxilus Schäm Dich, immer gleich zu prügeln! Bist doch selber nur ein Sklave!

Aufseher Prügel her, Prügel hin! Ich erfüll nur meine Pflicht! (zu den SkLaven) Los! Tempo-Tempo!

Die Sklaven (tragen alles aufs Schiff)

$\ulcorner$ Aufseher Los-los!

25 Toxilus (zum Publikum) Nachdem ich Euch alles erklärt habe, darf ich nun wohl gehen - ich muss auf das Schiff, um nachzusehen, ob alles richtig eingeladen wird Ich komme ${ }^{\ulcorner}$wieder, ${ }^{\urcorner}$wenn ich muss! (ab auf das Schiff) $\urcorner^{\urcorner}$

\| Aufseher (knallt mit der Peitsch)

IDiotima Oh saget ihm er knalle nicht so mit der Peitsch! Ich bin geschwächt -

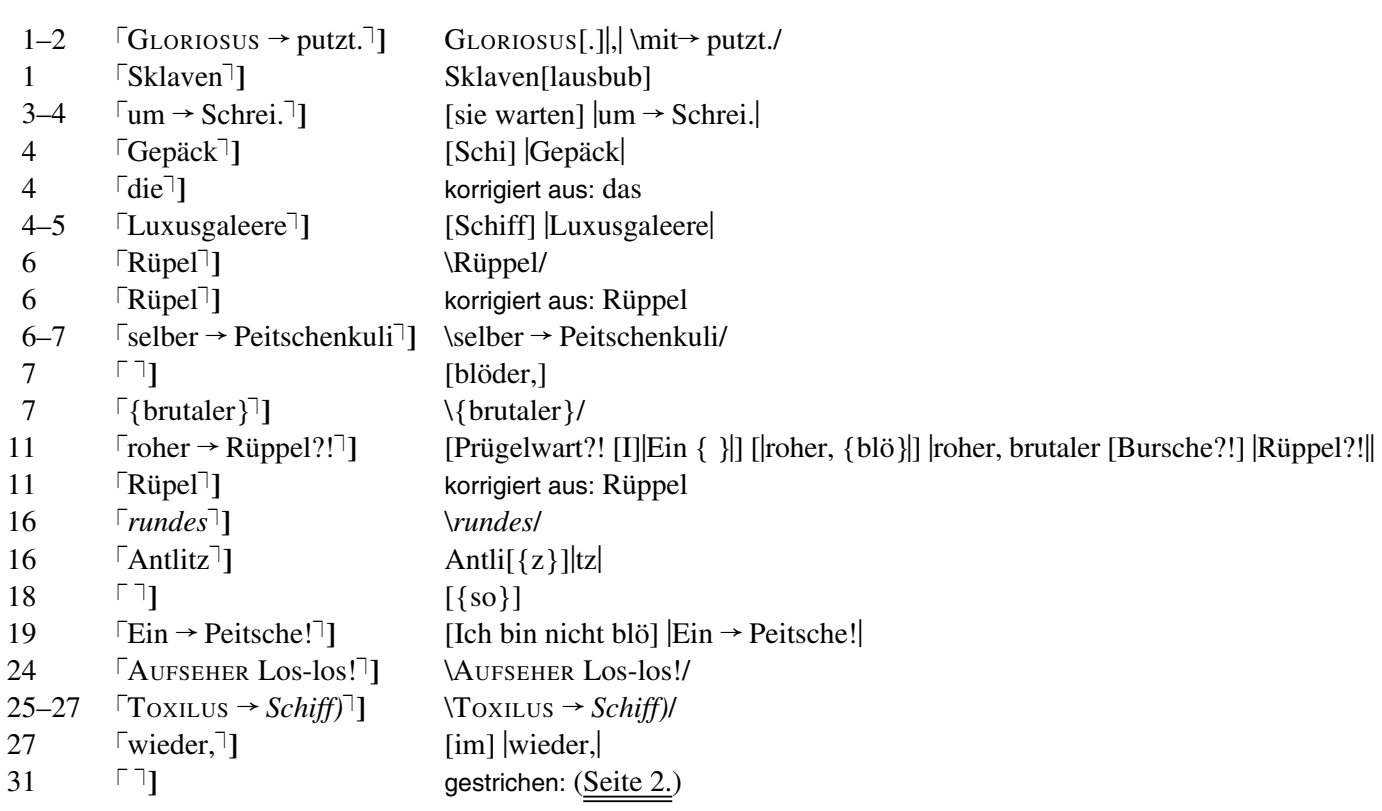


|| PAegnium (tritt vor) Gnädiger Herr!

GLORIOSUS Ich kann mich in meinem Schild nicht sehen. Wo bin ich? Du sollst

ÖLA 3/W $99-$ BS 29 a [7], BI. 1 meinen Schild so putzen, dass ich ihn als Spiegel benützen kann -- begreifs doch endlich, dass ich mit Mars verwandt bin! (er reicht ihm den Schild) Putz ihn, sonst erledig ich Dich, wie jene fünfhundert in Cappadozien im vorigen Herbst -- fünfhundert mit einem Streich, obwohl mein Schwert abgestumpft war!?

\| Idiotima (nimmt die Maske ab; eine verhärmte Frau $\ulcorner$ voller Angst $\urcorner$ wird $\ulcorner$ sichtbar -$\urcorner$ sie reicht die Maske einer $\ulcorner$ Sklavin und $\urcorner$ die Sklavinnen beschäftigen sich nun \ulcorner\urcorner mit der Maske; schminken sie und pudern sie und drehen ihr Löckchen)

IDIOTIMA (blickt zum Himmel empor)

Ach Wölklein in der Höh

$\| \quad$ Nur Du $\ulcorner$ erkennst $\urcorner$ mein $\ulcorner$ Weh: $\urcorner$

Mein Gatte $\ulcorner$ ist ein Berufsmensch.

ÖLA 3/W $99-$

Er liebt nur sein Schwert, seinen $\ulcorner$ Schild $\urcorner$, sein Panzer --

15 Was gilt ihm der Venusberg neben einem befestigten Hügel?

Nichts, oh nichts!

Er fürchtet nur immer, ob seine Rüstung auch richtig $\ulcorner$ glänzt.

Heut zieht er sich schon seit gestern an

Er legte sich garnicht zu Bett in der Nacht

Er zog sich nur an --

Ich frag mich oft:

Warum kennt mein Gatte keine Gemütlichkeit?

Gloriosus Ein böses Wort!

Viel lieber als in die Sommerfrische zög ich in einen flotten Krieg

Viel lieber würd ich blutige Taten vollbringen

Als friedlich meine Brust in der Sonne bräunen --

Denn $\left\ulcorner\right.$ meine Brust ${ }^{\urcorner}$sehnt sich nach $\ulcorner$der $\urcorner\ulcorner$befreienden $\urcorner$Tat!

Idiotima (so nebenbei) Ich hasse den Krieg.

Gloriosus Versündig Dich nicht! Wenn das ${ }^{\ulcorner\urcorner}$Mars hört!

IDIotima Lass mich aus mit Deinem Gott!

Wenn mein Vater kein Krösus wär

Wäre mein Gatte ein friedlicher Hirte

Aber das Geld meines Vaters lässt ihn nicht arbeiten --

So langweilt er sich $\|$ auf dem Felde der Ehre zu Tode.

35

Gloriosus (nimmt die Maske ab; ein feminines Gesicht, ängstliche Augen) Du nimmst den Mund voll, als hättest Du mir einen Sohn geschenkt.
ÖLA 3/W 98 -

BS 29 a [6], BI. 4

\begin{tabular}{|c|c|c|}
\hline $2-6$ & $\ulcorner$ GLORIOSUs $\rightarrow$ war! $\rceil$ & Textentlehnung Plautus, MG 1 und MG $^{2}$ \\
\hline 7 & $\ulcorner$ voller Angst $]$ & \voller Angst/ \\
\hline 7 & $\lceil$ sichtbar -$\urcorner]$ & sichtbar [)$]|-|$ \\
\hline 8 & $\ulcorner$ Sklavin und $\urcorner]$ & Sklavin[,]|und $\mid$ \\
\hline 8 & \ulcorner\urcorner$]$ & gestrichen: nun \\
\hline & $\lceil$ erkennst $\rceil]$ & [kennst] |erkennst| \\
\hline & $\ulcorner$ Weh: $\urcorner$ & [Leid:] |Weh:| \\
\hline & $\ulcorner$ ist $\rightarrow$ Berufsmensch. $\urcorner]$ & [[liebt] |sieht| nur sich.] [|sieht|] |ist $\rightarrow$ Berufsmensch.| \\
\hline & $\ulcorner$ Schild $\rceil]$ & [Helm] |Schild $\mid$ \\
\hline & 「glänzt. $\urcorner]$ & glänzt\./ \\
\hline & $\ulcorner$ meine Brust $\urcorner]$ & meinle/ [Herz] |Brust $\mid$ \\
\hline & $\ulcorner$ der $\urcorner$ & Ider/ \\
\hline & $\ulcorner$ befreienden $\urcorner]$ & befreiende $[\mathrm{r}]|\mathrm{n}|$ \\
\hline & \ulcorner\urcorner$]$ & [der] [|mein|] \\
\hline
\end{tabular}


$\ulcorner$ Idiotima (will schreien; aber die Sklavinnen setzen ihr nun \{wieder\} die Maske auf, und \{nähen dann $\}$ wieder am Saum ihres Kleides $)^{\urcorner}$

K.R. Thago (zu Lemniselenis) Wohl begreif ich Deine Trauer \ulcorner\urcorner$\|$ mein $\left\ulcorner\right.$ süsses, ${ }^{\urcorner}$teuerstes Geschöpf!

\| Denn ich fahr nun fort und lass Dich da.

Doch sei beruhigt:

Ich lass auch mein Geschäft da, Handel und Wandel, die Börs, das Kontor -Mögen die Papiere fallen oder sich heben Ich muss ruhen!

$\mathrm{Ja}$, ruhen --

Der Arzt hats mir verordnet, der Weise

Er kennt mein Leiden.

Es ist nicht der Ausfluss des üppigen Lebens

Sondern der Erregung über das Leben in Geschäften.

Verlieren regt auf

Aber verdienen noch mehr --

Und viel verdienen, das legt sich aufs Herz

Denn viel verdienen ist Schmerz

20 Teuer erkaufter Schmerz, Du Kind --

Lemniselenis Der Sommer mag kommen, der Herbst vergehen

Meine Lieb zu Euch wird immer bestehen

Denn Ihr habt mich gekauft.

$\|\ulcorner$ THaGo Lieb, sehr lieb - (er tätschelt ihre Wange)

25 Toxilus (erscheint auf dem Schiffe und springt auf den Kai) $\left.{ }^{\ulcorner}\right\urcorner$Euere Hochwohlgeborenen! \ulcorner\urcorner$\|$ Die Segel sind gesattelt, der Anker ist gelichtet, das Gepäck verpackt und die Ruder sind ruderbereit -- es schwimmt alles in Butter, schiffet Euch ein!

|| Idiotima Endlich! (sie steigt ein)

Gloriosus (zu Päg.) Her damit! - - Wo bin ich? $\ulcorner$ Ich seh mich \ulcorner\urcorner nicht! (er setzt seine Maske auf) Ich seh mich noch immer nicht! $\ulcorner$ Warte $\urcorner$ nur, wenn ich $\ulcorner$ heimkehr? , lass ich Dich blenden! (ab auf das Schiff)

PäGnIUM (nimmt die Maske ab; sieht ihm nach) Trottel! 「Idiot, Mörder - ${ }^{\ulcorner}$(ab in die Villa $)^{\urcorner}$

Thago (zu Lem) Kurz und gut, mit einem Wort: \ulcorner\urcorner$\|$ es wird höchste Zeit, dass ich einsteig und Du -- Du kehrst morgen wieder zu Dordalus zurück.

|| Lemniselenis (entsetzt) Was sagt Ihr?! (sie reisst sich die Maske ab) Wohin?! Zu Dordalus?!

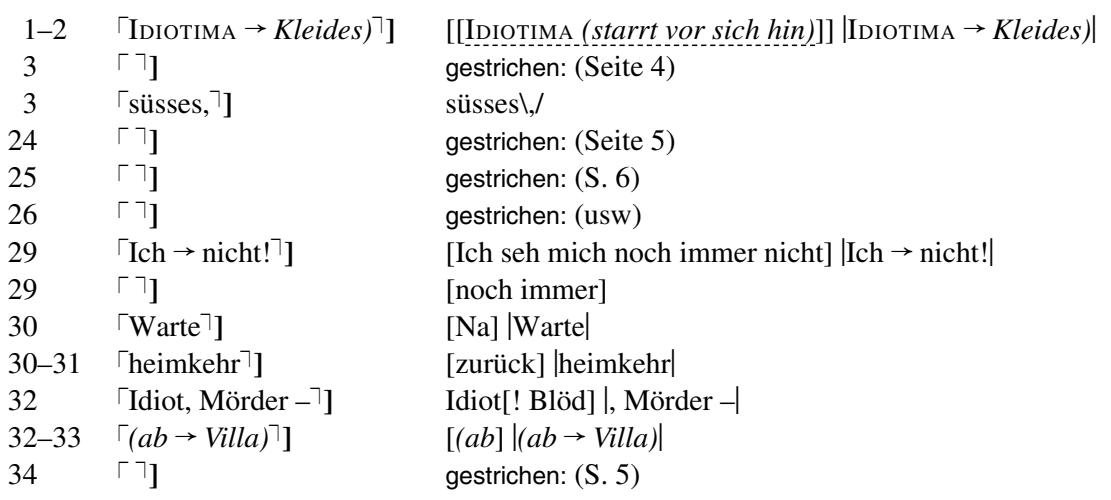


\| K.R. Thago Ja. Nach Pompeji.

LEMNISELENIS (wie zuvor) Ich soll wieder zum Sklavenhändler?! Ihr wollt mich abermals wieder weiterverkaufen?!

K.R. Thago Warum so entsetzt? Vielleicht kauft Dich ein Besserer, Schönerer, Reicherer --

|| LeMnisELENIS (unterbricht ihn) Es gibt keinen Reicheren als Euch! Oh, bringt mich nicht wieder auf den Sklavenmarkt! Es folget so selten was Besseres nach!

K.R. Thago Aber-aber, grosses Kind! Was hast Du Dir denn nur vorgestellt? Und ausserdem möcht man doch nur Dein Gutes --

LEMNISELENIS Wollet lieber das Schlechte, mein Herr!

Gewährt mir weiter Euere Huld

Ich bleib Euch nichts schuld.

Wenn Ihr heimkehrt von Euerer Sommerfahrt Wird von mir alles in bar bezahlt. Jeder Groschen ein Kuss Wenn ich nicht wieder auf den Sklavenmarkt muss --

K.R. Thago Wer weiss, ob ich zurückkehr? Ob das Schiff nicht versinkt? Wer befiehlt dem Meer, dem Sturm -- Neptun oder ich? Bin ich dem Neptun sein Vertrauter? Na also! Abgesehen davon, dass ich Dich jetzt ein halbes Jahr umsonst ernähren müsst! Vorsicht ist die Mutter der Weisheit und Sparsamkeit ist eine Weltanschauung. Verkenne mich nicht, mein Kind!

(Stille)

Lemniselenis Jetzt weiss ich nichtmehr, was ich glauben soll, Herr Präsident.

25 || ThaGo (nimmt sich feierlich die Maske ab; es ist kein Gesicht zu sehen - nur ein $\ulcorner$ Geldstück $\urcorner$ Glaub nicht der Gosse! \ulcorner\urcorner

\| Glaube mir

Glaub nicht den Geldlosen

Ohnehosen

$30 \quad$ Glaube den Reichen

Sie haben Recht!

Das Armselige

Wird immer vertan

35 Das Ewig-Geldliche

Zieht uns hinan!

$\|$ (Posaunenstoss)

K.R. Thago (kneift $\ulcorner$ Lem in die Wange) $\ulcorner า\urcorner$ $\mid \|$ Du bist unter Brüdern sechshundert Silberlinge wert. Verkauf Dich nur $\left\ulcorner\right.$ ja ${ }^{\urcorner}$nicht zu billig -- (er folgt IDiotima und GLORIOSUs auf das Schiff)

ÖLA 3/W $99-$ BS 29 a [7], BI. 6

ÖLA 3/W $109-$ BS 30 a, BI. 9
ÖLA 3/W 98 -

BS 29 a [6], BI. 5

ÖLA 3/W 96 BS 29 a [4], BI. 10

ÖLA 3/W 96 BS 29 a [4], BI. 10

ÖLA 3/W 98 BS 29 a [6], BI. 6

$\begin{array}{ll}26 & \ulcorner\text { Geldstück }] \\ 26 & \ulcorner\urcorner] \\ 32 & \ulcorner\urcorner] \\ 37-38 & \ulcorner(\text { Posaunenstoss } \rightarrow \text { Wange })\urcorner] \\ 38 & \ulcorner\text { Lem } \rightarrow \text { Wange })\urcorner] \\ 38 & \ulcorner\urcorner] \\ 39 & \ulcorner\text { ja }\urcorner] \\ 41 & \ulcorner\urcorner]\end{array}$

Geld $[\{\}] \mid$ stück

gestrichen: (S. 6)

[Ich kenn das Geschäft!]

$\backslash$ (Posaunenstoss $\rightarrow$ Wange)/

Lem[)] $\mid$ in $\rightarrow$ Wange) $\mid$

gestrichen: (S. 6.)

lja/

[(Posaunenstoss! $)]$ 
Toxilus $\ulcorner($ ins $\urcorner$ Orchester $)$ Darf man bitten, Herr Kapellmeister!

(Musik)

「K.R. THAGO ${ }^{\urcorner}$(steigt ein)

Matrosa Gute Erholung, frohe Fahrt!

5 Alle Sklaven (strömen mit Masken herbei, singen und winken dem Schiffe nach) $\ulcorner$ ᄀ

\| $\quad$ Keine Well auf der See

ÖLA 3/W 93 -

Und der Himmel blau

BS 29 a [1], BI. 13

Frohe Fahrt!

10 Keine Wolk in der Höh

Und die Luft so lau

Frohe Fahrt!

Keine Sorg in der Brust

Und im Herz nur Lust

15

Frohe Fahrt!

$\ulcorner$ Fahret hin, fahret her

(leise) Ertrinket im Meer!

$\ulcorner$ (laut) Frohe Fahrt!

20

AUFSEHER ( 'horchte perplex auf -- das Schiff ist nun verschwunden)

$\|\ulcorner\urcorner$ AufseHER $\ulcorner$ Was $\urcorner$ hör ich?! „Ertrinket im Meer“ -

ÖLA 3/W $98-$

$\|\left\ulcorner\right.$ Toxilus $\left.{ }^{\urcorner\ulcorner}\right\urcorner$Halt! Du wirst doch da nicht herumprügeln, wo wir Sklaven jetzt sozusagen untereinander sind?!

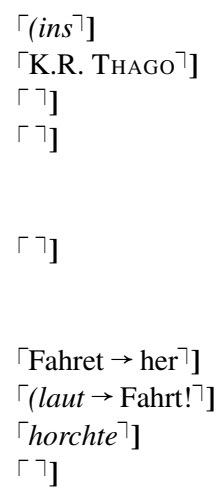


AufseHER Das ist mir wurscht!

$\ulcorner$ Toxilus $\urcorner$ Mir aber nicht!

AufseHer Das ist mir erst recht wurscht!

$\ulcorner$ Toxilus $\urcorner$ (ruhig) Halt den Mund.

5 Aufseher (braust auf) Was erlaubst Du Dir --

$\lceil$ Toxilus $\urcorner$ (unterbricht ihn) Kannst Du lesen?

AufseHER (perplex) Nein.

Toxilus Dann schau her -- (er zeigt ihm ein Dokument) Während der Abwesenheit unserer Herrschaft wurde ich, ich Toxilus, zum obersten Verwalter dieser Villa eingesetzt, ${ }^{\ulcorner}$verstanden? Denn ich geniesse das restlose Vertrauen meines Herrn, $\ulcorner$ verstanden?! $\urcorner$ Und hier hat mir nun jeder zu gehorchen, $\ulcorner$ denn $\urcorner$ ich bin die höchste Instanz, bitt ich mir aus! Also los-los, an die Arbeit! Rastet nicht, damit $\left\ulcorner\right.$ Ihr nicht ${ }^{\urcorner}$ rostet! Tempo-Tempo! `Und $\urcorner$ geprügelt wird $\left\ulcorner\right.$ jetzt da ${ }^{\urcorner}$nichtmehr, Du mazedonischer Büffel! Gib mir Dein Werkzeug, auf der Stell, von heut ab prügel nur ich! Los, her damit! Vorwärts!

Aufsener (gibt ihm widerwillig seine Peitsche) Werd glücklich. Jetzt möcht ich nur wissen, zuwas ich noch leb -- ich kann doch nur strafen, sonst hab ich ja nichts gelernt! \ulcorner\urcorner Ohne Arbeit kann ich nicht leben!

Toxilus Kannst Du reiten?

20 Aufseher (perplex) Reiten?

Toxilus Ja.

AufseHER Natürlich kann ich reiten! Ich bin ${ }^{\ulcorner} \operatorname{sogar}{ }^{\urcorner}$gewissermassen auf dem Pferd geboren --

|| Toxilus Man merkts noch immer! Also höre: Du reitest jetzt sofort nach Pompeji, und zwar zum Sklavenhändler Dordalus -- Du kennst ihn doch?

AufseHER Leider! Ich war ja selber mal seine Ware.

ToxiLus Ich auch. Ein $\ulcorner$ schäbiger $\urcorner$ Geizhals!

Aufseher Wenn ich kein Sklav wär, sondern ein freier Mann, dann tät ich dem Kerl was erzählen!

$\begin{aligned} 2 & \ulcorner\text { ToxiLus }\urcorner \\ 4 & \ulcorner\text { Toxilus }\urcorner] \\ 6 & \ulcorner\text { ToxiLus }\urcorner \\ 10 & \ulcorner\urcorner] \\ & \\ 11 & \ulcorner\text { verstanden?! }] \\ 11 & \ulcorner\text { denn }\urcorner] \\ 12 & \ulcorner\text { Ihr nicht }\urcorner \\ 13 & \ulcorner\text { Und }\urcorner] \\ 13 & \ulcorner\text { jetzt da }\urcorner \\ 18 & \ulcorner\urcorner]\end{aligned}$

$22\lceil\operatorname{sogar}\urcorner]$

$27\lceil$ schäbiger $\urcorner$
[ButLerus] |Toxilus|

[ButLERus] |TOXILUS| [ButLerus] |Toxilus|

[als Oberkammersklave gewissermassen, und zwar von unserem hochgeborenem Herrn K. R. Thago, dem Präsidenten des Romanisch-phönizischen Kreditinstituts, höchstpersönlich und eigenhändig --]

verstanden?!/

\denn/

[nichts] |Ihr nicht|

[Aber] |Und|

[hier] ljetzt da|

[Toxilus Ich weiss-ich weiss! Du hast die Peitschenvolksschul mit lauter Einser bestanden, hast die Prügelmatura summa cum laudis absolviert und hast sogar auf der Folterhochschul einige Semester studiert -- ich weiss-ich weiss!

AuFseHER Jaja, ich hatte eine goldene Jugend!

Toxilus Noch ist kein triftiger Grund zur Melancholie vorhanden --

AufseHER (unterbricht ihn)]

[ja] |sogar|

korrigiert aus: schäbbiger 
Toxilus Vorerst beherrsch Dich und erzähl ihm nur folgendes: einen schönen Gruss von unserem abwesendem Herrn und er hätt ihm ein Fräulein Hetäre zum Verkauf zu übergeben -- in Kommission! Er möcht sich aber das Fräulein bald abholen, denn wir haben hier kein Eis, auf das wir es legen könnten, und da es heiss ist, verdirbts uns noch am End -- (er grinst) Fahr ab!

AufseHer Geht in Ordnung! Wird prompt erledigt.

Toxilus Reit nur zu! Dass Du mir aber Dein Pferd nicht zu sehr $\ulcorner$ schindest!

AuFSEHER Ich? Ich sollt ein Tier misshandeln?! Für was hältst Du mich?! (entrüstet $a b)$

10 (Während der vorigen Szene sind auch alle SkLaVen, ausser Lemniselenis und Matrosa, $a b$ )

LEMNISELENIS (sitzt am Fusse einer Säule und weint still vor sich hin)

Toxilus (betrachtet sie; zu Matrosa) Was hat sie denn?

Matrosa Sie weint.

15 Toxilus Warum?

Matrosa Es ist ihr hier so gut gegangen und jetzt hat sie Angst vor der Zukunft.

Toxilus Aber-aber! Einen solchen schiechen alten Kracher, wie meinen gnädigen Herrn, den wird doch solch \ulcorner\urcorner liebliches $\ulcorner$ Ding $\urcorner$ immer wieder leicht finden! Direkt über Nacht!

20 Matrosa Unberufen!

Toxilus Sie kriegt auch junge fesche stramme --

LEMNISELENIS (unterbricht ihn) Also nur das nicht!

Toxilus (perplex) Was hör ich?

$\|$ Matrosa ( $z u$ Toxilus) Sie möcht von der männlichen Jugend nichts wissen. Wenns nach ihr ging, tät sie sich einen Herrn Gebieter aus dem Greisenasyl holen.

Toxilus Aha! Capisco! Einen gichtigen Greis, wacklig, zittrig, hirnrissig, der mit dem einem Haxen bereits durch die Unterwelt hatscht und von dem sich gar federleicht allerhand erben lässt -- schau-schau! Mit himmelblauen Pupillen blickt die Unschuld geschäftstüchtig in die $\ulcorner$ Welt. Jaja $\urcorner$, im Kontor der Tugend wird mit der Jugend gar häufig gewuchert!

LEMNISELENIS Ihr versteht mich nur halb.

Toxilus Möglich. Denn die eine Hälfte, dass Ihr nämlich von der männlichen Jugend überhaupt nichts wissen wollt -- diese Hälfte kapier ich überhaupt nicht!

LEMNiSELENIS Diese Hälfte kann ich mir nicht leisten. 'Darum: ${ }^{7}$

Ich möcht einen Mann von hundert Jahren

Mit dem könnt ich dann Schlitten fahren

Ich tät ihn pflegen, tränken, füttern

Tag und Nacht nur ihn bemüttern --

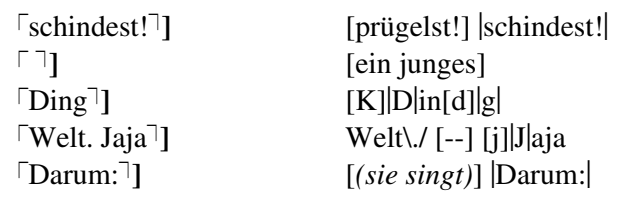


Ich möcht einen Mann, der bald nimmer ist

Der bald verbrannt wird und zwar ganz gewiss

Ich opfer dann dem Pluto eins-zwei Gulden

$\ulcorner$ Und bin sie los, alle Schulden --

5

Denn: was hat man von seiner Jugend ohne Freiheit? Nichts! Und wie wird man frei? Nur durch Geld! Auch die Freiheit ist nämlich nur ein käuflicher Artikel -und ohne Groschen pfeiff ich auf meine Jugend! Denn Jugend ist Freiheit und Freiheit ist Geld!

10

Darum:

Ich möcht einen Mann von hundert Jahren

Mit dem würd ich dann in die Freiheit fahren

Ich tät ihn immer pflegen, hegen

15

Lang tät er ja nimmer leben --

Es lebe die Jugend!

Matrosa ( $z u$ Toxilus) Sie ist eine geborene Krankenschwester.

$\|$ ToxiLus (grinst) Allerdings.

20

LEMNiSELENIS Ihr dürft nicht annehmen, dass ich mit unerlaubten Mitteln, als da sind: böse Kräuter, Schlangengift, etcetera -- das Ableben eines gebrechlichen Gebieters beschleunigen wollte. Ich würde auch nimmer ein massgebliches Wort in seinem Testament fälschen, aber ich tät ihm die Schrecken der Unterwelt ausmalen, und das fiele mir leicht, denn ich müsst ihm doch nur vom Schicksal der Sklaven auf der Oberwelt berichten. Die Haare würden ihm alle gen Himmel stehen und er würd mich vor lauter Grauen garantiert freikaufen, um nicht in der Unterwelt als Sklave verhandelt zu werden, als ein Ding mit menschlichen Allüren -- Oh Götter, es fällt mir immer schwerer an Euere Güte zu glauben! Sagt mir: gibt es Euch denn überhaupt? Und wenn es Euch gibt, warum seid Ihr denn so böse zu mir? Wie gern würde ich gut sein --

Toxilus Das ist ein Traum.

Matrosa ( $z u$ Toxilus) Sie hat eine zarte Seele.

Toxilus ( $z u$ Matrosa) Was verstehst Du unter Seele?

LEMNISELENIS Was sich aus einem fortsehnt.

35 (Stille)

Toxilus ( $z u$ Lemniselenis) Wo kommt Ihr her?

$\ulcorner$ Lemniselenis Mein Papa ist ein Parasit.

Er betreibt das gleiche Geschäft, das meine Ahnen

Von ältesten Zeiten her betrieben haben

$40 \quad$ Und er pflegt es mit viel Talent.

Ich kenne keinen meiner Vorfahren

\footnotetext{
4-18 「Und $\rightarrow$ Krankenschwester. $]] \quad \|[$ Drum nehm ich einen hundertjährgen Mann Wenn ich dadurch nur ganz frei [sein] |werden| kann! Ohne Groschen pfeif ich auf die Jugend dieser Welt! Jugend ist Freiheit, Freiheit Geld!

Matrosa Sie ist eine geborene Krankenschwester.] |Und $\rightarrow$ Krankenschwester.|

37-331,5 「LEMNISELENIS $\rightarrow$ überbieten. $\urcorner]$

Textentlehnung Plautus, PER ${ }^{5}$
} 
Der sich nicht durch Parasiten-Kunst gemästet hätt.

Grosspapa, Urgrosspapa, Ur-ur und noch ein Urpapa

Sie alle haben stets

Von fremder Kost gelebt

5 U Und an Gefrässigkeit konnt sie keiner überbieten.

$\ulcorner$ Meine Freiheit wurd ein Opfer ihrer $\ulcorner$ Gier: $\urcorner$

ÖLA 3/W 109

BS 30 a, BI. 15

Papa verkaufte mich als Sklavenkind um ein opulentes Menu $?$

Er konnt den Fasanen, Muränen und Hummern nicht $\ulcorner$ widerstehen $\urcorner$

$\left\ulcorner\right.$ Sie haben ihn überwältigt, die geschlachteten Tiere ${ }^{\urcorner}$

Sie wohnen in ihm und sitzen auf seinem Willen --

Er kennt nur die Lust

Sonst nichts.

Toxilus Und Ihr habt Euch so einfach verkaufen lassen?

LEMNISELENIS Man muss seinen Eltern gehorchen. Ausserdem wurd ich nicht gefragt

15 und ich hätt auch nicht antworten können, denn ich war erst drei Jahre alt.

Toxilus Seltsam sind die Schicksale der Sklaven!

Sie sind sich alle gleich, auch wenn sie anders sind --

Auch ich verlor meine Freiheit als dreijähriger Knirps

Ich wurd bei Babylon gefangen --

20 Lemniselenis Ach, Ihr seid ein Perser?

Toxilus Keine Ahnung! Ob Perser, Grieche, Inder, Aegypter -- was weiss ich, woher ich stamm!

Lemniselenis Schad! Denn Perser sind interessant --

Toxilus Wieso?

25 Lemniselenis Perser sind alle schwarz und ich bin blond.

(Stille)

Toxilus ( $z u$ Lemniselenis; er lächelt) Wenn Ihr es wünscht, dann bin ich ein Perser --

LEMNISELENIS (klatscht in die Hände) 'Fein!

30 Matrosa Wie man freiwillig ein Perser sein möcht, das geht über meinen Horizont.

|| LEMNISELENIS Warum?

Matrosa Weil alle Perser böse Menschen sind.

Lemniselenis (lacht) Böse Menschen gibts überall!

Toxilus (starrt Lemniselenis an) Mir tuts nur leid, dass ich noch keine hundert Jahr

35 alt bin -- (er lächelt)

LEMNISELENIS (stutzt und schaut ihn gross an) \ulcorner\urcorner

Toxilus Weil ich Euch dann freikaufen würde.

Matrosa Warum?

Toxilus ( $z u$ Lemniselenis) Weil Ihr mir gefällt.

40 Matrosa (erhebt sich; $z u$ Lemniselenis) $\left\ulcorner\right.$ Kommt, Herrin, ${ }^{\urcorner}$gehen wir!

LEMNISELENIS (hört nicht auf sie, sondern fixiert Toxilus) Ihr würdet mich freikaufen?

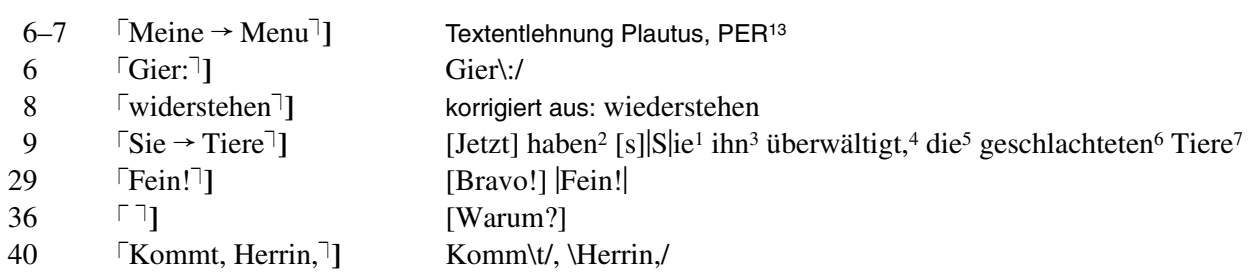


Toxilus Was kostet Ihr denn?

Lemniselenis Soviel ich weiss, sechshundert Silberlinge.

Toxilus Potz Pluto! Das ist ein Vermögen!

LEMNISELENIS (lächelt) Bin ichs nicht wert?

5 Matrosa ( $z u$ Lemniselenis) Los-los, Herrin! Das fängt sich immer so an: „Ihr gefällt mir“ und „Bin ichs nicht wert?“ Ich bitt Euch, macht keine Dummheiten, Ihr seid eine brave Hetär und jener ist ein Sklav -- diese Verbindung schickt sich nicht, göttlich, menschlich, gesetzlich nicht -- Ihr werdet Euch noch ins Unglück stürzen!

LEMNiselenis (sieht Toxilus unbeirrt an) Wenn Ihr mich freikaufen würdet, würd ich immer bei Euch bleiben. Ohne Zwang.

Matrosa (verzweifelt) Schaut Euch da nicht so an, Ihr verliert ja noch die Köpf!

Toxilus Ich schau nicht weg.

LEMNISELENIS (lächelt) Ich auch nicht.

15 Toxilus (zuckt plötzlich zusammen) Au! (er fasst sich ans Herz und windet sich etwas)

LEMNISELENIS (erschrickt) Was ist? Was habt Ihr?

Toxilus (leise) Mir scheint, ich bin verwundet -- so ein stechender Schmerz --

LEMNISELENis Tuts weh?

20 Toxilus (lächelt) Nein.

(Die Luft klingt)

Lemniselenis (blickt empor und ruft) Amor, Amor! -- Dort fliegt er, dort!

Matrosa Um aller Götter Willen! Jetzt aber rasch in das Haus, Fenster und Türen versperrt, sonst schiesst er sie auch noch an, dieser unberechenbare Bursch! (sie zieht LEMNISELENIS rasch mit sich $\ulcorner\text { in die Villa })^{\urcorner}$

(Vorhang)

\begin{tabular}{lll}
\hline 12 & $\ulcorner$ Ihr $\rightarrow$ Köpf! $\urcorner]$ & [es dreht sich [ja] $\mid$ doch $\mid$ um Euere Köpf!] $\mid \mathrm{Ihr} \rightarrow$ Köpf!| \\
25 & $\ulcorner$ in $\rightarrow$ Villa $)]]$ & in $[$ s Haus $)] \mid$ die Villa $)$
\end{tabular}



Repliken und Notizen zum II. und III. Akt

ÖLA 3/W 98 - BS 29 a [6], Bl. 1

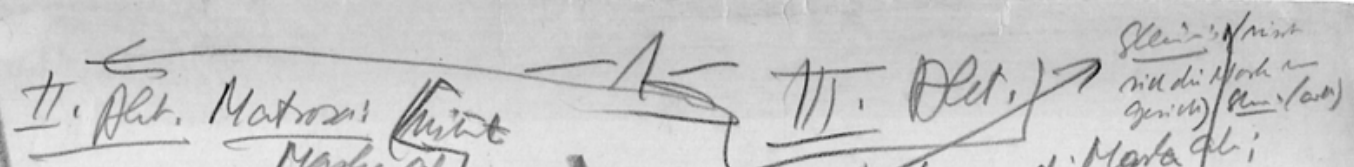
ERSTER AKT.

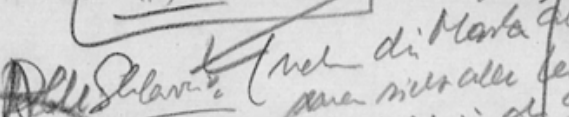
sence sichale feide soleft is al geseh,

Es brginut mit cinur Stender Bied: Bi C d: ston, (inis)

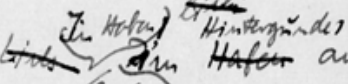

lintes

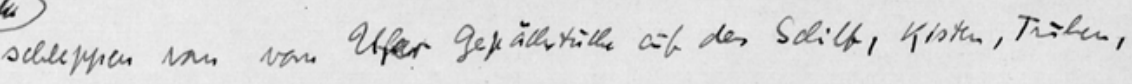

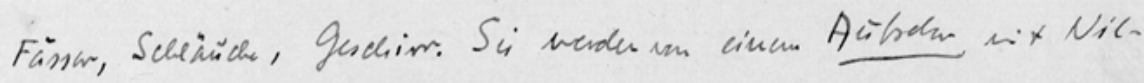

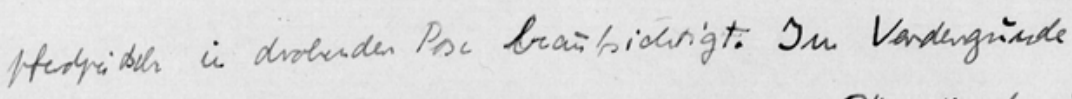

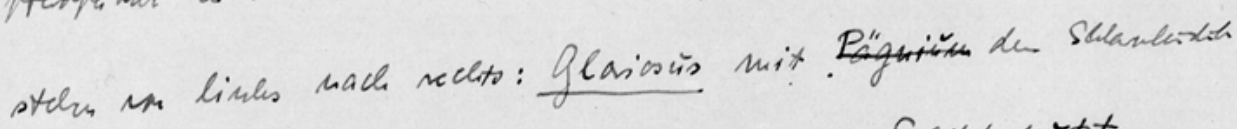

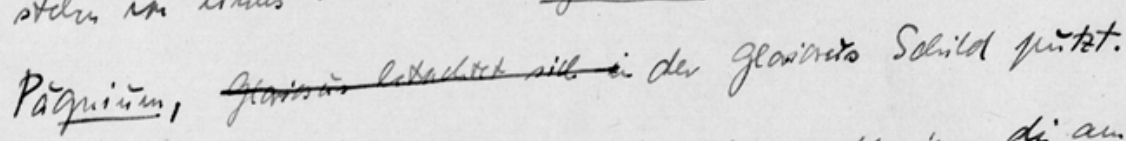

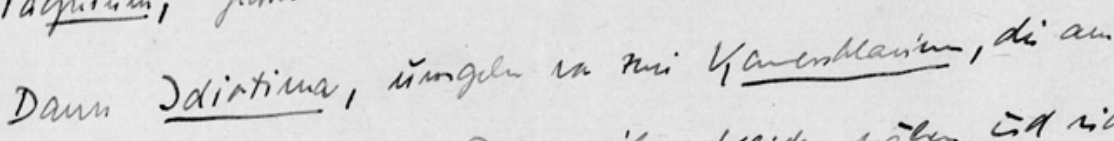

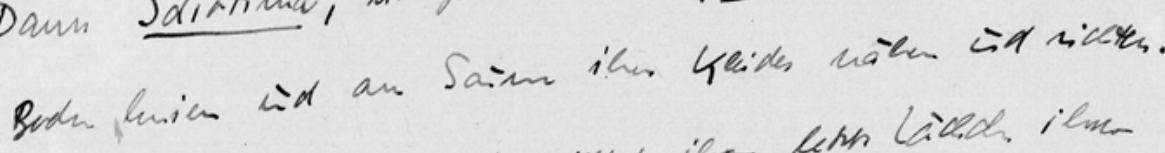

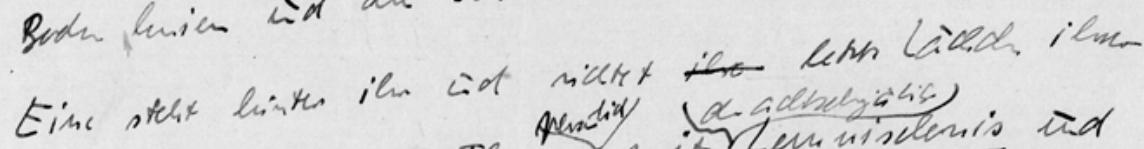

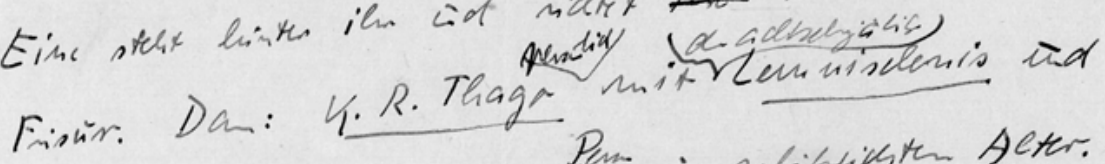

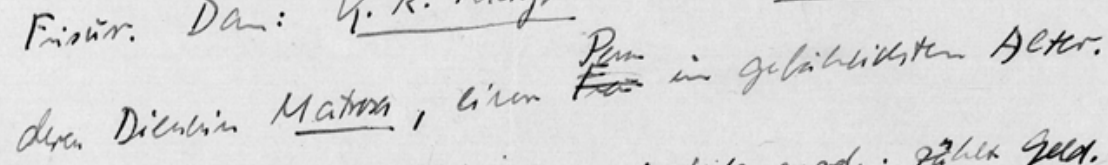

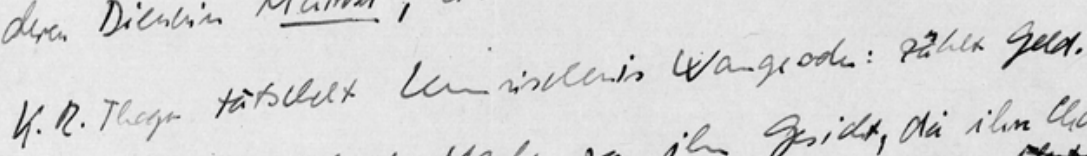

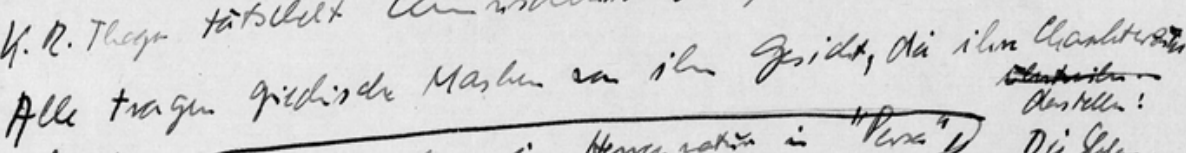

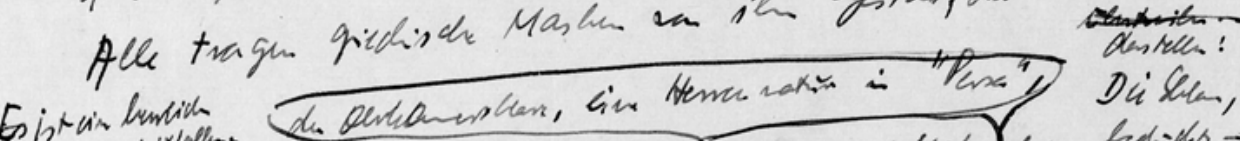

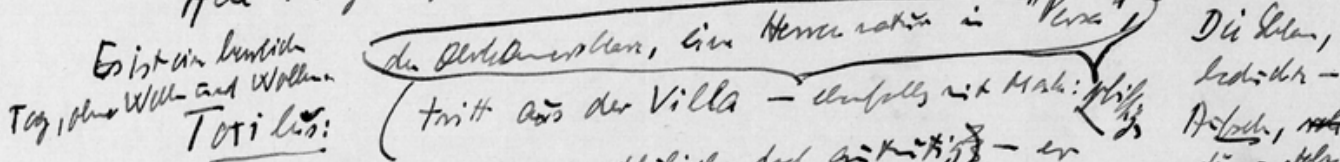

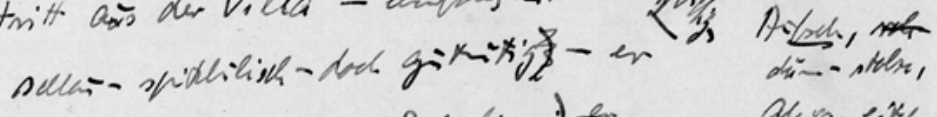

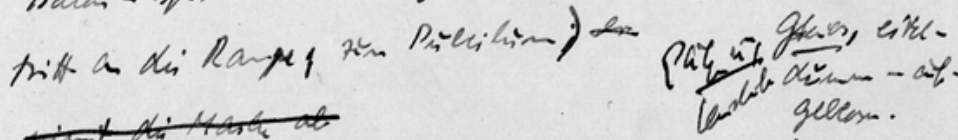

$$
\begin{aligned}
& \text { Lelining, } \\
& \text { Ah Provgis } \\
& \text { begiume ide sit civen fitat as Plarkas: } \\
& \text { geschimint- } \\
& \text { Tager, Risicisen } \\
& \text { 4 Dh Pillilinm! }
\end{aligned}
$$

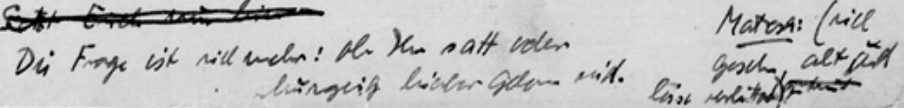

1

334 


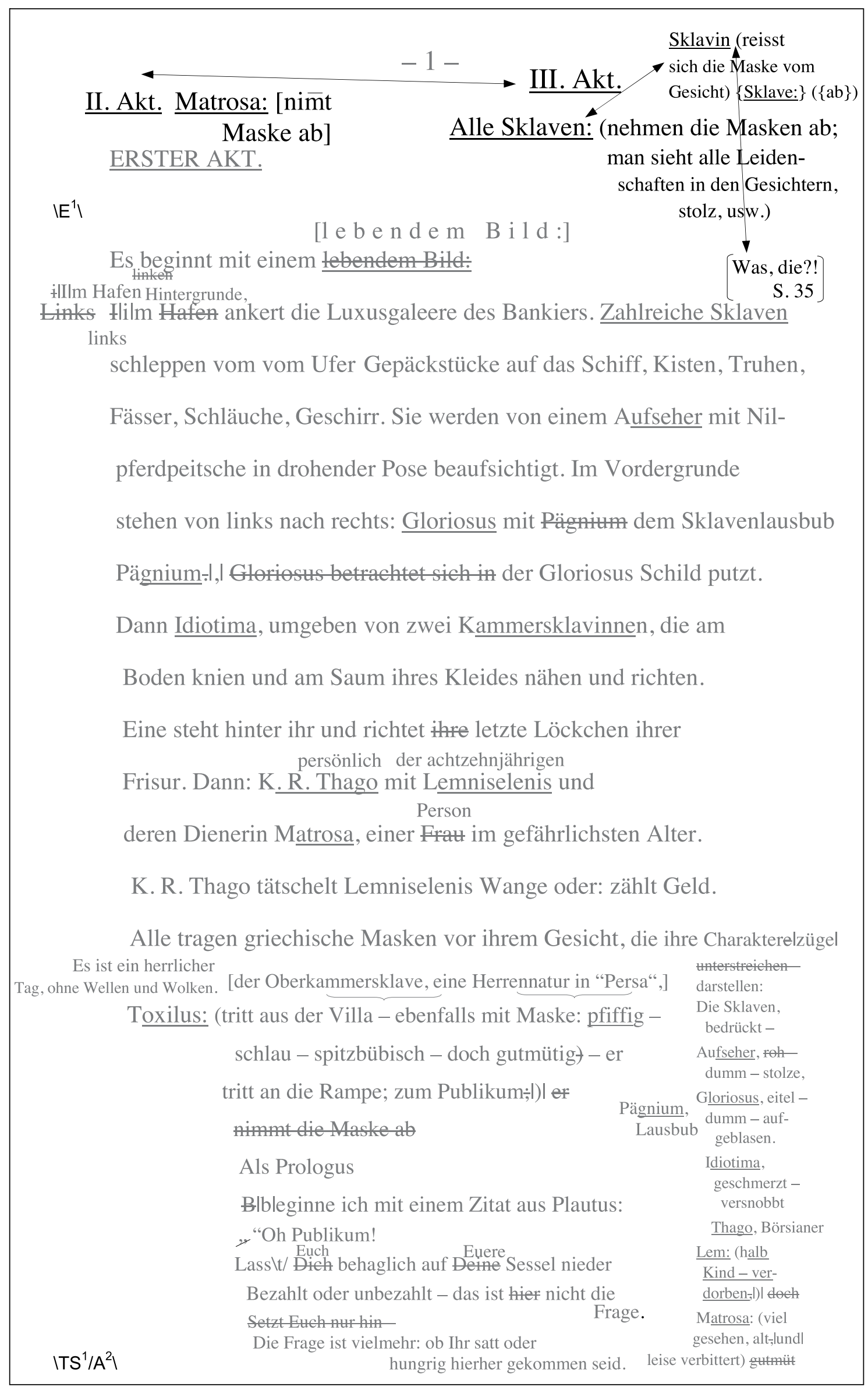


\|EIN SKLAVENB ALL

mit Gesang und Tanz in drei Akten von $\ulcorner$ Ödön $\urcorner$ von $\ulcorner$ Horváth?

ÖLA 3/W 109 BS 30 a, BI. 1

\section{|| PERSONEN}

5

K.R. Thago, ein punischer Bankier

Idiotima, seine Tochter

Gloriosus, deren Mann

Toxilus, Oberkammersklave

10 Lemniselenis $\urcorner$, eine Hetäre

Matrosa, deren Dienerin

Der Aufseher

Paegnium, ein Sklavenlausbub

Bagnio, ein entlaufener Sklave

15

Der Praetor von Pompeji

Dordalus, Sklavenhändler

Sklaven und Sklavinnen.

\section{ZEIT}

Im Altertum. Innerhalb vierundzwanzig Stunden.

\section{|| SCHAUPLATZ}

25

Kleiner Privathafen vor einer Villa am Meer, unweit von Pompeji. Die Villa ist der ländliche Lustsitz des reichen punischen Bankiers K.R. Thago, eines naturalisierten Römers. Hier wohnt er im Frühling mit seiner Tochter Idiotima und derem Gatten Gloriosus.

30 Rechts im Vordergrunde sieht man einige Säulen der Villa, links im Hintergrunde liegt das Meer.

\section{$\|$ ERSTER AKT}

35 Das Stück beginnt mit einem le bendem Bild:

Im Hafen, links im Hintergrunde, ankert die Luxusgaleere des Bankiers. ZAHLREICHE SKLAVEN UND SKLAVINNEN schleppen vom Ufer Gepäckstücke auf das Schiff, Kisten, Truhen, Fässer, Schläuche, Geschirr. Sie werden von einem AufSEHER mit Nilpferdpeitsche in drohender Pose beaufsichtigt. Im Vordergrunde stehen von links nach rechts: Gloriosus, stolz auf den Knauf seines Schwertes gestützt; neben ihm kniet der Sklavenlausbub PAEGNIUM und putzt einen Schild; dann IDIOTIMA, umgeben von DRei Kammersklavinnen, die noch etwas am Saum ihres Kleides zu nähen haben und ihr mit einer $\ulcorner$ Brennschere $\urcorner$ auch noch Löckchen ins Haar brennen; dann K.R. THAGO persönlich mit der achtzehnjährigen Hetäre LEMNISELENIS und deren

$\begin{array}{rll}2 & \ulcorner\text { Ödön }\urcorner] & {[\mathrm{O}] \mid \text { Ö|dön }} \\ 2 & \ulcorner\text { Horváth }\urcorner] & \text { Horv[a]|á|th } \\ 10 & \ulcorner\text { Lemniselenis }\urcorner] & \text { Lemnis[i]|e|lenis } \\ 43 & \ulcorner\text { Brennschere }\urcorner] & \text { korrigiert aus: Brennscheere }\end{array}$


Dienerin Matrosa, einer Person im gefährlichsten Alter, die sich nun etwas im Hintergrund hält, denn der Bankier tätschelt gerade der Hetäre Wange. Ganz im Vordergrunde steht Toxilus als Prologus, in $\ulcorner$ einen $\urcorner$ feierlichen $\urcorner$ weissen Radmantel gehüllt, eine Pergamentrolle in der Hand. Es ist ein herrlicher Tag, ohne Wellen und 5 Wolken.

Alle Personen tragen griechische Masken, die die wesentlichen Züge ihrer Charaktere, $\ulcorner$ so wie $\urcorner$ man sich selbe landläufig vorstellt, darstellen sollen. So steht nun Toxilus mit der typischen Prologmaske vor dem Publikum. K.R. THAGo, ein gütiger Börsianer, LeMniselenis, ein freches Dirnchen, Matrosa, eine alte Dirnchenmutter, Idiotima, gepflegt, $\ulcorner$ versnobt $\urcorner$, mit dem leerem Lächeln der \ulcorner\urcorner Gesellschaftsdame, Gloriosus, ei-||tel, dumm und aufgeblasen, PAEgnium, ein pfiffiger Spitzbub, der Aufseher roh und niederträchtig, die SKLAVEn und SkLAVInNen, niedergedrückt, bemitleidenswert armselig, so wie es sich eben gehört.

[Es ist ein herrlicher Tag, ohne Wellen und Wolken.

15

$\ulcorner$ Toxilus (zum Publikum)

Als Prologus

Beginne ich mit einem Zitat aus Plautus:

„Oh Publikum!

Lasst Euch behaglich auf Euere Sitze nieder

Bezahlt oder unbezahlt -- das ist nicht die Frage

Die Frage ist vielmehr:

Ob Ihr satt oder hungerig ${ }^{\ulcorner}$hierher ${ }^{\urcorner}$gekommen seid.

Wer bereits genachtmahlt hat, der hat das bessere Teil erwählt

Doch wer hungert, esse sich an unseren Witzen satt --

Aber wem zu Hause das Nachtmahl steht

Der ist ein Narr

Ein grosser Narr

Dass er uns zulieb nüchtern hergekommen ist! ${ }^{67}$

(er nimmt seine Maske ab und entledigt sich seines Mantels)

Huh, ist mir heiss!

Verzeiht, dass ich mich demaskiere

Doch hoffe ich, dass Ihr mich auch ohne Maske goutieren werdet --

Erlaubt, dass ich mich vorstelle:

$\ulcorner$ Eigentlich bin ich zwar eine Herrennatur

Die $\ulcorner$ eben $\urcorner$ nur im $\ulcorner$ Sklavenstande $\urcorner$ lebt

Ein Mann voll geistiger Kraft und Gewandtheit

Voll Witz und Gesundheit

\begin{tabular}{|c|c|c|}
\hline 3 & $\lceil$ einen $\rceil]$ & eine $[m]|n|$ \\
\hline 3 & $\ulcorner$ feierlichen $\rceil$ & feierliche $[m]|n|$ \\
\hline 7 & $\lceil$ so wie $\rceil]$ & korrigiert aus: sowie \\
\hline 10 & $\lceil$ versnobt $\rceil$ & korrigiert aus: versnobbt \\
\hline 10 & \ulcorner\urcorner$]$ & [grossen] \\
\hline 14 & $\ulcorner$ Es $\rightarrow$ Wolken. $\urcorner]$ & Es $\rightarrow$ Wolken./ \\
\hline $16-29$ & $\left\lceil\right.$ ToxiLus $\rightarrow$ ist! $\left.{ }^{‘}\right]$ & Textentlehnung Plautus, $\mathrm{POE}^{1}$ \\
\hline 23 & $\lceil$ hierher $\urcorner]$ & hierไher/ \\
\hline $36-338,1$ & $\ulcorner$ Eigentlich $\rightarrow$ unterordnet $\urcorner]$ & Textentlehnung Plautus, PER ${ }^{1}$ \\
\hline 37 & $\lceil$ eben $\urcorner]$ & leben/ \\
\hline 37 & $\ulcorner$ Sklavenstande $\urcorner]$ & Sklavenstandle/ \\
\hline
\end{tabular}


Dem sich seine Umgebung willig unterordnet ${ }^{7}$

Die Sklaven nämlich, deren Oberster ich bin --

Jedoch auch -- (leise) -- meine Herrschaft!

Ich sag es leise, denn sie steht hier hinter mir und soll es nicht hören! Sonst setzt es was ab auf meinen Buckel und das wollt ${ }^{\top} \mathrm{Ihr}$ mir doch nicht ${ }^{\urcorner}$gönnen! (laut) Erlaubt nun, dass ich Euch die Szenerie erläutere: Ihr seht hier ein lebendes Bild. Rechts die Villa meiner Herrschaft und links im Hintergrunde das Meer -- dort ankert die Luxusgaleere meines Herrn, des Präsidenten des Romanisch-phönizischen Kreditinstitutes, K.R. Thago -- (er deutet auf K.R. THAGO) -- er ist ein gebürtiger Punier, hat sich aber in Rom naturalisieren lassen und allerhand Geld gemacht. Er verabschiedet sich soeben von seiner Fräulein Hetäre, namens Lemniselenis -- die Alte dahinter ist ihre Dienerin Matrosa, ein treuer Schatten! Jawohl, mein Herr verabschiedet sich, denn er ${ }^{\ulcorner}$segelt ${ }^{\top}$ mit seiner Tochter Idiotima und derem Gatten Gloriosus nach Kreta in die $\ulcorner$ Sommerfrisch $\urcorner$, denn Kreta ist zur Zeit der letzte Schrei. $\ulcorner$ Die Herrschaften $\urcorner$ segeln noch heute, sie warten nur noch, bis die Sklaven das viele Gepäck auf die Luxusgaleere gebracht haben. Der ${ }^{\ulcorner R \ddot{i}-}$ pel $\urcorner$ dort hinten mit der Peitsche, das ist der Aufseher, ein $\left\ulcorner\right.$ roher, ${ }^{\urcorner}$niederträchtiger 'Mensch $\urcorner^{\urcorner}-$

AufseHer (fällt ihm ins Wort) Was bin ich?!

20 Toxilus Hast es nicht gehört? Zweimal sag ichs nicht.

AUFSEHER Ich hin ein roher, niederträchtiger Mensch?!

\| Toxilus Hab ich das gesagt?

Aufseher \ulcorner\urcorner Jawohl!

Toxilus Dann wirds schon stimmen --

AufseHer Es stimmt aber nicht! Da, schau her -- (er reisst seine Maske herunter, ein rundes, gutmütiges Gesicht wird sichtbar) Ist das das Antlitz eines Peitschenkulis?!

Toxilus (perplex) Sieh da! $\ulcorner$ Komisch, dass $\urcorner$ ich \ulcorner\urcorner Dein Gesicht noch nie gesehen $\ulcorner$ hab $\urcorner$-- hm. Nein, roh und niederträchtig sieht es nicht aus, eher ein bisserl blöd --

AufseHer (braust jähzornig auf) Ein solches Wort noch und -- (er hebt drohend seine Peitsche)

Toxilus (herrscht ihn an) Schäm Dich, immer nur die Peitsche, die Peitsche, die Peitsche! Bist doch selber nur ein Sklav!

Aufseher $\ulcorner\text { Sklave }\urcorner^{7}$ her, Peitsche hin! Ich erfüll ja nur meine Pflicht! (er knallt mit der Peitsche und brüllt die SKLAVEN, die die Gepäckstücke tragen, an) Vorwärts-vorwärts! Nur nicht getrödelt, gewurstelt, geschlafen, sonst weck ich Euch auf, Sklavenpack!

\begin{tabular}{|c|c|}
\hline\ulcorner\urcorner$]$ & {$[--]$} \\
\hline$\ulcorner$ Ihr $\rightarrow$ nicht $\urcorner]$ & doch $^{3} \operatorname{Ihr}^{1}$ mir $^{2}$ nicht $^{4}$ \\
\hline$\ulcorner$ segelt $\urcorner$ & [fährt jetzt] |segelt| \\
\hline$\ulcorner$ Sommerfrisch $\urcorner$ & Sommerfrisch[e] \\
\hline$\lceil$ Die Herrschaften $\rceil]$ & [Sie] |Die Herrschaften| \\
\hline$\lceil$ Rüpel $\rceil$ & korrigiert aus: Rüppel \\
\hline$\ulcorner$ roher, $\rceil]$ & roherl,/ \\
\hline$\lceil$ Mensch $\rceil$ & [Bursche] |Mensch| \\
\hline\ulcorner\urcorner$]$ & gestrichen: $\mathrm{b}$ \\
\hline$\lceil$ Komisch, dass $\urcorner]$ & [Eigentlich hab] |Komisch, dass $\mid$ \\
\hline\ulcorner\urcorner$]$ & [ja] \\
\hline$\lceil\mathrm{hab}\urcorner]$ & \hab/ \\
\hline$\lceil$ Sklave $\rceil]$ & [Peitsche] |Sklave| \\
\hline
\end{tabular}


Die Sklaven (tragen ihre Lasten auf das Schiff)

AUFSEHER (zählt die an ihm vorbeigeschleppten Gepäckstücke) -- 84, 85, 86, 87 -los-los! Wir haben noch 164 Stück! (er knallt wieder mit der Peitsche)

IDIOTIMA (zuckt etwas zusammen)

5 Toxilus (zum Publikum) Nachdem ich Euch alles erklärt habe, darf ich nun wohl gehen -- ich muss nämlich auf das Schiff, um nachzusehen, ob auch alles richtig verstaut wird. Ich komme wieder, wenn ich muss! (rasch ab auf das Schiff)

AufseHer (brüllt einen ALTEN SKLAVEn grimmig an) Tempo-tempo! 107, 108, 109 -hast nicht gehört, altes Stück Elend?! (er knallt abermals mit der Peitsche)

10 || Idiotima $\ulcorner$ (zuckt abermals zusammen $)\urcorner$ Oh saget ihm, er knalle nicht so mit der Peitsche!

Er schlage lieber, dann gibts nicht diesen schrillen Ton!

Meine Nerven vertragen keine Disharmonien

Ich bin geschwächt --

15 Gloriosus Paegnium! Wo bleibt mein Schild?

Paegnium (reicht ihm den Schild) Aufzuwarten, gnädiger Herr!

$\ulcorner$ GLORIOSus (blickt auf seinen Schild, wie in einen Spiegel) Ich kann mich in meinem Schild nicht sehen. Wo bin ich? Du sollst meinen Schild so putzen, dass ich ihn als Spiegel benützen kann -- begreifs doch endlich, dass ich mit Mars verwandt bin! (er reicht ihm wieder seinen Schild) Putz ihn, sonst erledig ich Dich, wie jene fünfhundert in Kappadozien im vorigen Herbst -- fünfhundert mit einem Streich, obwohl mein Schwert abgestumpft war! ${ }^{7}$

Paegnium (putzt eifrig den Schild)

IDiotima (nimmt langsam ihre Maske ab: eine verhärmte, frühgealterte Frau wird sichtbar)

DiE KAMMERSKLAVINNEN (stürzen sich sofort eifrigst auf die Maske, schminken und pudern sie)

IDIOTIMA (blickt zum Himmel empor)

Ach, Wölklein in der Höh

Nur du erkennst mein Weh:

Mein Gatte ist ein Berufsmensch.

Er liebt nur sein Schwert, seinen Schild, seinen Panzer --

Was gilt ihm der Venusberg neben einem befestigten Hügel?

Nichts, oh nichts!

Er fürchtet nur immer, ob seine Rüstung auch richtig $\ulcorner$ glänzt.

Heut zieht er sich schon seit gestern an

Er legte sich garnicht zu Bett in der Nacht

Er zog sich nur an --

Ich frag mich oft:

Warum kennt mein Gatte keine Gemütlichkeit?

GLORIOSus Ein böses Wort!

Viel lieber als in die Sommerfrische zög ich in einen flotten Krieg

Viel lieber würd ich blutige ${ }^{\ulcorner}$Dinge $^{\urcorner}$vollbringen

$\begin{array}{lll}10 & \ulcorner\text { (zuckt } \rightarrow \text { zusammen })\urcorner] & \backslash[\text { zuck }] \mid \text { zuckt } \rightarrow \text { zusammen } \mid / \\ 17-22 & \ulcorner\text { GLoRIOSUS } \rightarrow \text { war! }\urcorner] & \text { Textentlehnung Plautus, MG } 1 \text { und MG² } \\ 35 & \ulcorner\text { glänzt. }\urcorner] & \text { glänzt } \backslash . / \\ 43 & \ulcorner\text { Dinge }\urcorner] & {[\text { Taten] } \mid \text { Dinge } \mid}\end{array}$


Als friedlich meine Brust in der Sonne bräunen --

Denn $\left\ulcorner\right.$ meine Brust ${ }^{\urcorner}$sehnt sich nach $\ulcorner$der $\urcorner\ulcorner$befreienden $\urcorner$Tat!

IDIOTIma ( $\ulcorner$ einfach $\urcorner$ ) Ich hasse den Krieg.

GLoriosus Versündig Dich nicht! Wenn das $\left.{ }^{\ulcorner}\right\urcorner$Mars hört!

5 Idiotima Lass mich aus mit Deinem Gott!

Wenn mein Vater kein Krösus wär

Wäre mein Gatte ein friedlicher Hirte

Aber das Geld meines Vaters lässt ihn nicht arbeiten --

So langweilt er sich auf dem Felde der Ehre zu Tode.

10 || GLORIOSUs (reisst sich wütend die Maske herab: ein feminines Gesicht wird sichtbar mit ängstlichen Augen; er fixiert unsicher IDIOTIмA; plötzlich herrscht er sie an)

ÖLA 3/W $109-$ BS 30 a, BI. 8 Du nimmst den Mund voll, als hättest Du mir einen Sohn geschenkt!

IDIOTIMA (will schreien, doch die KAMMERSKLAVINNEN binden ihr rasch, fast $\ulcorner$ gewalttätig, ${ }^{\urcorner}$die frisch hergerichtete Maske um)

K.R. Thago ( $z u$ LEMniselenis)

Wohl begreif ich Deine Trauer, mein süsses, teuerstes Geschöpf!

Du kostspieliges, Du --

Denn ich fahr nun fort und lass Dich da.

Doch sei beruhigt:

Mögen die Papiere fallen oder sich heben

Ich muss ruhen!

Der Arzt hats mir verordnet, der Weise

Er kennt mein Leiden.

Es ist nicht der Ausfluss des üppigen Lebens

Sondern der Erregung über das Leben in Geschäften.

Verlieren regt auf

Aber verdienen noch mehr --

Und viel verdienen, das legt sich aufs Herz

Denn viel verdienen ist Schmerz

Teuer erkaufter Schmerz, Du Kind --

Lemniselenis Der Sommer mag kommen, der Herbst vergehen

Meine Lieb zu Euch wird immer bestehen

35 Denn Ihr habt mich gekauft.

$\ulcorner$ K.R. THAGO $\urcorner$ Lieb, sehr lieb -- (er tätschelt wieder ihre Wange)

Toxilus (erscheint rasch an Bord des Schiffes und springt auf den Kai) Euere Hochwohlgeborenen! Die Segel sind gesattelt, der Anker gelichtet, das Gepäck verpackt und die Ruder sind ruderbereit -- es schwimmt alles in Butter, schiffet Euch ein!

IDiotima Endlich! (ab auf das Schiff)

$\begin{array}{lll}2 & \ulcorner\text { meine Brust }\urcorner] & \text { meinle/ }[\text { Herz] } \mid \text { Brust } \mid \\ 2 & \ulcorner\text { der }\urcorner] & \mid \text { der/ } \\ 2 & \ulcorner\text { befreienden }\urcorner] & \text { befreiende }[\mathrm{r}]|\mathrm{n}| \\ 3 & \ulcorner\text { einfach }\urcorner] & {[\text { so nebenbei }] \text { einfach } \mid} \\ 4 & \ulcorner\urcorner] & {[\text { der] }[\mid \text { mein|] }} \\ 13-14 & \ulcorner\text { gewalttätig, }\urcorner] & \text { gewalttätig } \backslash, / \\ 23 & \ulcorner\urcorner \text { ] } & \text { [Ja, ruhen --] } \\ 36 & \ulcorner\text { K.R. THAGO }\urcorner] & \text { korrigiert aus: K. R. THAGO }\end{array}$


Gloriosus ( $z u$ PAegnium) Her damit! (er nimmt ihm seinen Schild ab und $\|$ betrachtet sich in ihm; entsetzt, denn er sieht sich ohne Maske) Was?! Das soll ich sein?! (er herrscht PAEGNIUM an) Ich seh mich noch immer nicht! Wart nur, Bube, wenn ich heimkehr, lass ich Dich blenden! (rasch ab auf das Schiff)

5 Paegnium (sieht ihm nach; leise) Idiot! (er nimmt seine Maske ab, ein mageres, trotziges Knabengesicht wird sichtbar; er fächelt sich mit der Maske und wischt sich mit dem Arm den Schweiss von der Stirne)

K.R. Thago ( $z u$ Lemniselenis) Kurz und gut, mit einem Wort: es wird höchste Zeit, dass ich einsteig und $\mathrm{Du}$-- Du kehrst morgen wieder zu Dordalus zurück.

Lemniselenis (entsetzt) Was sagt Ihr?! Wohin?! Zu Dordalus?!

K.R. Thago Ja. Nach Pompeji.

LEMNISELENIS (wie zuvor) Ich soll wieder zum Sklavenhändler?! Ihr wollt mich abermals wieder weiterverkaufen?! (sie reisst sich die Maske ab: ein schönes Kind mit traurigen Augen und einem frühverbittertem Zug starrt K.R. THAGO verzweifelt

15 an)

K.R. Thago (stutzt unwillkürlich etwas) Warum so verzweifelt? Vielleicht kauft Dich ein Besserer, Schönerer, Reicherer --

LEMNISELENIS (unterbricht ihn) Es gibt keinen Reicheren als Euch!

Oh, bringt mich nicht wieder auf den Sklavenmarkt!

$20 \quad$ Es folget so selten was Besseres nach!

K.R. Thago Aber-aber, grosses Kind! Was hast Du Dir denn \ulcorner\urcorner vorgestellt? Und ausserdem möcht man doch nur Dein Gutes --

Lemniselenis Wollet lieber das Schlechte, mein Herr!

Gewährt mir weiter Euere Huld

25 Ich bleib Euch nichts schuld.

Wenn Ihr heimkehrt von Euerer Sommerfahrt

Wird von mir alles in bar bezahlt.

Jeder Groschen ein Kuss

Wenn ich nicht wieder auf den Sklavenmarkt muss --

30 K.R. Thago Wer weiss, ob ich zurückkehr? Ob das Schiff nicht versinkt? Wer befiehlt dem Meer, dem Sturm -- Neptun oder ich? Bin ich dem Neptun sein Vertrauter? Na also! Abgesehen davon, dass ich Dich jetzt ein halbes Jahr umsonst ernähren müsst! Vorsicht ist die Mutter der Weisheit und Sparsamkeit ist eine Weltanschauung. Verkenne mich nicht, mein Kind!

35 (Stille)

Lemniselenis Jetzt weiss ich nichtmehr, was ich glauben soll, Herr Präsident.

\| K.R. Thago (nimmt langsam die Maske ab; er hat überhaupt kein Gesicht) LEMNISELENIS (starrt ihn ausser sich $\ulcorner$ an) $\urcorner$

K.R. Thago (feierlich)

$40 \quad$ Glaub nicht der Gosse

Glaube mir

Glaub nicht den Geldlosen

Ohnehosen

Glaube den Reichen

45

Sie haben Recht!

Das Armselige

\begin{tabular}{lll}
\hline 21 & \ulcorner\urcorner$]$ & [nur] \\
38 & $\ulcorner$ an $)]$ & an[,]l)| [voll Grauen und Eckel)]
\end{tabular}


Wird immer vertan

Das Ewig-Geldliche

Zieht uns hinan!

LEMNISELENIS (schreit auf) Nein!! (sie verbirgt ihr Gesicht in den Händen)

5 K.R. Thago (setzt sich langsam wieder seine Maske auf und streicht LEMNISELENIS über die Haare) Du bist unter Brüdern sechshundert Silberlinge wert. Verkauf dich nur ja nicht zu billig -- (ab auf das Schiff)

Toxilus ( $z u$ K.R. Thago) Gute Erholung, frohe Fahrt! (ins Orchester) Darf man bitten, Herr Kapellmeister!

$10 \quad$ (Musik erklingt)

Alle Sklaven (ausser Lemniselenis, singen und winken dem verschwindendem Schiffe nach)

Keine Well auf der See

Und der Himmel blau

Frohe Fahrt!

Keine Wolk in der Höh

Und die Luft so lau

Frohe Fahrt!

Keine Sorg in der Brust

20

Und im Herz nur Lust

Frohe Fahrt!

\| Fahret hin, fahret her

(leise) Ertrinket im Meer!

Ertrinket im Meer!

AUFSEHER (horchte perplex auf, das Schiff ist nun verschwunden; er brüllt) Was hör ich?! „Ertrinket im Meer“?! Was soll der Text?! Beim Jupiter, das halt ich nicht aus! (er hebt seine Peitsche)

$\ulcorner$ Toxilus $\urcorner\ulcorner\urcorner$ Halt! Du wirst doch da nicht herumprügeln, wo wir Sklaven jetzt sozusagen untereinander sind?!

AufseHER Das ist mir wurscht!

$\ulcorner$ ToxiLus $\urcorner$ Mir aber nicht!

AufSEHER Das ist mir erst recht wurscht!

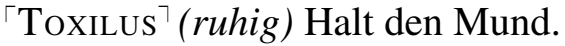

35 Aufseher (braust auf) Was erlaubst Du Dir --

$\ulcorner$ ToxiLus $\urcorner$ (unterbricht ihn) Kannst Du lesen?

Aufseher (perplex) Nein.

Toxilus Dann schau her -- (er zeigt ihm ein Dokument) Während der Abwesenheit unserer Herrschaft wurde ich, ich Toxilus, zum obersten Verwalter dieser Villa eingesetzt, \ulcorner\urcorner$\ulcorner$ verstanden?! Denn ich geniesse das restlose Vertrauen meines

\begin{tabular}{|c|c|c|}
\hline 29 & $\lceil$ Toxilus $\urcorner]$ & [Butlerus] |Toxilus| \\
\hline 29 & \ulcorner\urcorner$]$ & [(zum AufseHER $)]$ \\
\hline 32 & $\ulcorner$ Toxilus $\urcorner]$ & [Butlerus] |Toxilus| \\
\hline 34 & $\ulcorner$ Toxilus $]$ & [Butlerus] |Toxilus| \\
\hline 36 & $\lceil$ Toxilus $\urcorner]$ & [Butlerus] |Toxilus| \\
\hline 0 & \ulcorner\urcorner$]$ & $\begin{array}{l}\text { [als Oberkammersklave gewissermassen, und zwar von unserem hochgebore- } \\
\text { nem Herrn K. R. Thago, dem Präsidenten des Romanisch-phönizischen Kredit- } \\
\text { instituts, höchstpersönlich und eigenhändig --] }\end{array}$ \\
\hline & $\lceil$ verstanden?! $]$ & verstanden?!// \\
\hline
\end{tabular}


Herrn, verstanden?! Und hier hat mir nun jeder zu gehorchen, $\ulcorner$ denn $\urcorner$ ich bin die höchste Instanz, bitt ich mir aus! Also los-los, an die Arbeit! Rastet nicht, damit $\left\ulcorner\right.$ Ihr nicht ${ }^{\urcorner}$rostet! Tempo-Tempo! $\ulcorner$Und $\urcorner$geprügelt wird $\left\ulcorner\right.$jetzt da ${ }^{\urcorner}$nichtmehr, Du mazedonischer Büffel! Gib mir Dein Werkzeug, auf der Stell, von heut ab prügel nur ich! Los, her damit! Vorwärts!

AufseHER (gibt ihm widerwillig seine Peitsche) Werd glücklich. Jetzt möcht ich nur wissen, zuwas ich noch leb -- ich kann doch nur strafen, sonst hab ich ja nichts gelernt! \ulcorner\urcorner Ohne Arbeit kann ich nicht leben!

Toxilus Kannst Du reiten?

10 Aufseher (perplex) Reiten?

Toxilus Ja.

AufseHER Natürlich kann ich reiten! Ich bin $\left\ulcorner\right.$ sogar ${ }^{\urcorner}$gewissermassen auf dem Pferd geboren --

|| Toxilus Man merkts noch immer! Also höre: Du reitest jetzt sofort nach Pompeji, und zwar zum Sklavenhändler Dordalus -- Du kennst ihn doch?

AufseHER Leider! Ich war ja selber mal seine Ware.

ToxiLus Ich auch. Ein $\ulcorner$ schäbiger $\urcorner$ Geizhals!

Aufseher Wenn ich kein Sklav wär, sondern ein freier Mann, dann tät ich dem Kerl was erzählen!

Toxilus Vorerst beherrsch Dich und erzähl ihm nur folgendes: einen schönen Gruss von unserem abwesendem Herrn und er hätt ihm ein Fräulein Hetäre zum Verkauf zu übergeben -- in Kommission! Er möcht sich aber das Fräulein bald abholen, denn wir haben hier kein Eis, auf das wir es legen könnten, und da es heiss ist, verdirbts uns noch am End -- (er grinst) Fahr ab!

25 Aufseher Geht in Ordnung! Wird prompt erledigt.

Toxilus Reit nur zu! Dass Du mir aber Dein Pferd nicht zu sehr ${ }^{\ulcorner}$schindest!

AuFseHER Ich? Ich sollt ein Tier misshandeln?! Für was hältst Du mich?! (entrüstet $a b)$

(Während der vorigen Szene sind auch Alle Sklaven, ausser Lemniselenis und

Matrosa, $a b)$

LEMNISELENis (sitzt am Fusse einer Säule und weint still vor sich hin)

Toxilus (betrachtet sie; zu MAtrosa) Was hat sie denn?

Matrosa Sie weint.

Toxilus Warum?

Matrosa Es ist ihr hier so gut gegangen und jetzt hat sie Angst vor der Zukunft.

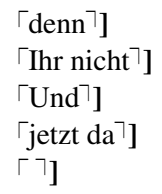

Idenn/

[nichts] |Ihr nicht|

[Aber] |Und|

[hier] ljetzt da|

[Toxilus Ich weiss-ich weiss! Du hast die Peitschenvolksschul mit lauter Einser bestanden, hast die Prügelmatura summa cum laudis absolviert und hast sogar auf der Folterhochschul einige Semester studiert -- ich weiss-ich weiss!

AufSeher Jaja, ich hatte eine goldene Jugend!

ToxiLus Noch ist kein triftiger Grund zur Melancholie vorhanden --

AufseHER (unterbricht ihn)]

[ja] |sogar|

korrigiert aus: schäbbiger

[prügelst!] |schindest!| 
Toxilus Aber-aber! Einen solchen schiechen alten Kracher, wie meinen gnädigen Herrn, den wird doch solch \ulcorner\urcorner liebliches $\ulcorner$ Ding $\urcorner$ immer wieder leicht finden! Direkt über Nacht!

Matrosa Unberufen!

5 Toxilus Sie kriegt auch junge fesche stramme --

LEMNISELENIS (unterbricht ihn) Also nur das nicht!

Toxilus (perplex) Was hör ich?

$\|$ Matrosa ( $z u$ Toxilus) Sie möcht von der männlichen Jugend nichts wissen. Wenns nach ihr ging, tät sie sich einen Herrn Gebieter aus dem Greisenasyl holen.

ÖLA 3/W 109 BS 30 a, Bl. 13

Toxilus Aha! Capisco! Einen gichtigen Greis, wacklig, zittrig, hirnrissig, der mit dem einem Haxen bereits durch die Unterwelt hatscht und von dem sich gar federleicht allerhand erben lässt -- schau-schau! Mit himmelblauen Pupillen blickt die Unschuld geschäftstüchtig in die $\ulcorner$ Welt. Jaja $\urcorner$, im Kontor der Tugend wird mit der Jugend gar häufig gewuchert!

LEMNISELENIS Ihr versteht mich nur halb.

Toxilus Möglich. Denn die eine Hälfte, dass Ihr nämlich von der männlichen Jugend überhaupt nichts wissen wollt -- diese Hälfte kapier ich überhaupt nicht!

LEMNisELENIS Diese Hälfte kann ich mir nicht leisten.

'Darum: $:$

20 Ich möcht einen Mann von hundert Jahren

Mit dem könnt ich dann Schlitten fahren

Ich tät ihn pflegen, tränken, füttern

Tag und Nacht nur ihn bemüttern --

Ich möcht einen Mann, der bald nimmer ist

Der bald verbrannt wird und zwar ganz gewiss

Ich opfer dann dem Pluto eins-zwei Gulden

$\ulcorner$ Und bin sie los, alle Schulden --

Denn: was hat man von seiner Jugend ohne Freiheit? Nichts! Und wie wird man frei? Nur durch Geld! Auch die Freiheit ist nämlich nur ein käuflicher Artikel -und ohne Groschen pfeiff ich auf meine Jugend! Denn Jugend ist Freiheit und Freiheit ist Geld!

Darum: 
Ich möcht einen Mann von hundert Jahren

Mit dem würd ich dann in die Freiheit fahren

Ich tät ihn immer pflegen, hegen

Lang tät er ja nimmer leben --

5

Es lebe die Jugend!

Matrosa ( $z u$ Toxilus) Sie ist eine geborene Krankenschwester.

$\|$ Toxilus (grinst) Allerdings.

LEMNISELENIS Ihr dürft nicht annehmen, dass ich mit unerlaubten Mitteln, als da sind: böse Kräuter, Schlangengift, etcetera -- das Ableben eines gebrechlichen Gebieters beschleunigen wollte. Ich würde auch nimmer ein massgebliches Wort in seinem Testament fälschen, aber ich tät ihm die Schrecken der Unterwelt ausmalen, und das fiele mir leicht, denn ich müsst ihm doch nur vom Schicksal der Sklaven auf der Oberwelt berichten. Die Haare würden ihm alle gen Himmel stehen und er würd mich vor lauter Grauen garantiert freikaufen, um nicht in der Unterwelt als Sklave verhandelt zu werden, als ein Ding mit menschlichen Allüren -- Oh Götter, es fällt mir immer schwerer an Euere Güte zu glauben! Sagt mir: gibt es Euch denn überhaupt? Und wenn es Euch gibt, warum seid Ihr denn so böse zu mir? Wie gern würde ich gut sein --

Toxilus Das ist ein Traum.

Matrosa ( $z u$ Toxilus) Sie hat eine zarte Seele.

Toxilus ( $z u$ Matrosa) Was verstehst Du unter Seele?

LEMNISELENIS Was sich aus einem fortsehnt.

(Stille)

Toxilus ( $z u$ Lemniselenis) Wo kommt Ihr her?

$\ulcorner$ Lemniselenis Mein Papa ist ein Parasit.

Er betreibt das gleiche Geschäft, das meine Ahnen

Von ältesten Zeiten her betrieben haben

Und er pflegt es mit viel Talent.

Ich kenne keinen meiner Vorfahren

Der sich nicht durch Parasiten-Kunst gemästet hätt.

Grosspapa, Urgrosspapa, Ur-ur und noch ein Urpapa

Sie alle haben stets

Von fremder Kost gelebt

35 Und an Gefrässigkeit konnt sie keiner überbieten.

$\left\ulcorner\right.$ Meine Freiheit wurd ein Opfer ihrer ${ }^{\ulcorner}$Gier:

Papa verkaufte mich als Sklavenkind um ein opulentes Menu $\urcorner$

Er konnt den Fasanen, Muränen und Hummern nicht ${ }^{\ulcorner}$widerstehen $\urcorner$

${ }^{\ulcorner}$Sie haben ihn überwältigt, die geschlachteten Tiere ${ }^{\urcorner}$

Sie wohnen in ihm und sitzen auf seinem Willen --

Er kennt nur die Lust

Sonst nichts.

ToxiLus Und Ihr habt Euch so einfach verkaufen lassen?

$\begin{array}{ll}\text { 26-35 } & \text { 「LEMNISELENIS } \rightarrow \text { überbieten. }\urcorner] \\ 36-37 & \ulcorner\text { Meine } \rightarrow \text { Menu }\urcorner \\ 36 & \ulcorner\text { Gier: }\urcorner] \\ 38 & \ulcorner\text { widerstehen }\urcorner \\ 39 & \ulcorner\text { Sie } \rightarrow \text { Tiere }\urcorner]\end{array}$

Textentlehnung Plautus, PER 5 Textentlehnung Plautus, PER ${ }^{13}$

Gier\:/

korrigiert aus: wiederstehen

[Jetzt] haben ${ }^{2}[\mathrm{~s}]|\mathrm{S}| \mathrm{ie}^{1}$ ihn $^{3}$ überwältigt, ${ }^{4} \mathrm{die}^{5}$ geschlachteten $^{6}$ Tiere $^{7}$ 
LEMNiSELENIS Man muss seinen Eltern gehorchen. Ausserdem wurd ich nicht gefragt und ich hätt auch nicht antworten können, denn ich war erst drei Jahre alt.

ToxiLus Seltsam sind die Schicksale der Sklaven!

Sie sind sich alle gleich, auch wenn sie anders sind --

5 Auch ich verlor meine Freiheit als dreijähriger Knirps Ich wurd bei Babylon gefangen --

Lemniselenis Ach, Ihr seid ein Perser?

Toxilus Keine Ahnung! Ob Perser, Grieche, Inder, Aegypter -- was weiss ich, woher ich stamm!

Lemniselenis Schad! Denn Perser sind interessant --

Toxilus Wieso?

LEMniselenis Perser sind alle schwarz und ich bin blond.

(Stille)

Toxilus (zu Lemniselenis; er lächelt) Wenn Ihr es wünscht, dann bin ich ein Perser --

LEMNISELENIS (klatscht in die Hände) 'Fein!

Matrosa Wie man freiwillig ein Perser sein möcht, das geht über meinen Horizont.

\| LEMNISELENIS Warum?

Matrosa Weil alle Perser böse Menschen sind.

Toxilus (starrt Lemniselenis an) Mir tuts nur leid, dass ich noch keine hundert Jahr alt bin -- (er lächelt)

LEMNISELENIS (stutzt und schaut ihn gross an) \ulcorner\urcorner

Toxilus Weil ich Euch dann freikaufen würde.

25 Matrosa Warum?

Toxilus ( $z u$ LemNiselenis) Weil Ihr mir gefällt.

Matrosa (erhebt sich; $z u$ Lemniselenis) $\ulcorner$ Kommt, Herrin, $\urcorner$ gehen wir!

LEMNISELENIS (hört nicht auf sie, sondern fixiert Toxilus) Ihr würdet mich freikaufen?

Toxilus Was kostet Ihr denn?

Lemniselenis Soviel ich weiss, sechshundert Silberlinge.

Toxilus Potz Pluto! Das ist ein Vermögen!

LEMNISELENis (lächelt) Bin ichs nicht wert?

Matrosa ( $z u$ Lemniselenis) Los-los, Herrin! Das fängt sich immer so an: „Ihr gefällt mir“ und „Bin ichs nicht wert?“ Ich bitt Euch, macht keine Dummheiten, Ihr seid eine brave Hetär und jener ist ein Sklav -- diese Verbindung schickt sich nicht, göttlich, menschlich, gesetzlich nicht -- Ihr werdet Euch noch ins Unglück stürzen!

LEMNISELENIS (sieht Toxilus unbeirrt an) Wenn Ihr mich freikaufen würdet, würd ich immer bei Euch bleiben. Ohne Zwang.

Matrosa (verzweifelt) Schaut Euch da nicht so an, ${ }^{\ulcorner}$Ihr verliert ja noch die Köpf! Toxilus Ich schau nicht weg.

LEMNISELENIS (lächelt) Ich auch nicht.

$\begin{array}{ll}16 & \ulcorner\text { Fein! }] \\ 23 & \ulcorner\urcorner] \\ 27 & \ulcorner\text { Kommt, Herrin, }\urcorner] \\ 41 & \ulcorner\text { Ihr } \rightarrow \text { Köpf! }]\end{array}$
[Bravo!] |Fein!|

[Warum?]

Komm\t/, \Herrin,/

[es dreht sich [ja] |doch| um Euere Köpf!] |Ihr $\rightarrow$ Köpf!| 
Toxilus (zuckt plötzlich zusammen) Au! (er fasst sich ans Herz und windet sich etwas)

LEMNISELENIS (erschrickt) Was ist? Was habt Ihr?

Toxilus (leise) Mir scheint, ich bin verwundet -- so ein stechender Schmerz --

5 Lemniselenis Tuts weh?

Toxilus (lächelt) Nein.

(Die Luft klingt)

LeMniselenis (blickt empor und ruft) Amor, Amor! -- Dort fliegt er, dort!

Matrosa Um aller Götter Willen! Jetzt aber rasch in das Haus, Fenster und Türen versperrt, sonst schiesst er sie auch noch an, dieser unberechenbare Bursch! (sie zieht LEMNISELENIS rasch mit sich $\ulcorner\text { in die Villa })^{\urcorner}$

\section{(Vorhang)}

\section{$\|$ ZWEITER AKT}

${ }^{\urcorner}$Es ist Nacht geworden, der Mond scheint und das Meer summt. ToxiLus tritt aus

der Villa, hält vor den Säulen und blickt in die menschenleere Welt hinaus.

Toxilus Ich kann nicht schlafen.

Oh, Lemniselenis -- warum hast Du so einen langen Namen?

Woher soll sich ein armer Bursche die Zeit nehmen, um Dich immer wieder aussprechen zu können? Du bist zu lang für einen Bettler.

Wie gern würd ich Dich freikaufen, um Dein Sklave werden zu dürfen, zu sollen, zu müssen -- aber sechshundert Silberling! Oh Du mein armer Toxilus! Woher nehmen und nicht stehlen?

Matrosa (kommt aus der Villa; unterdrückt) He, hallo!

Toxilus (schrickt etwas zusammen) Ach, Du bists! Was willst Du?

Matrosa Nur auf ein Wort. Ich weiss, Du bist mir böse, weil ich Fenster und Türen versperrt hab, damit Du nicht zu meiner Herrin kannst --

Toxilus Willst Du sie nun öffnen?

Matrosa Nein.

35 Toxilus Dann fahr ab und lass mich allein!

Matrosa Ich fahr nicht ab, denn das verbietet mir mein $\ulcorner$ Mitleid.

$\|$ Toxilus (perplex) Dein was?

Matrosa Mein Mitleid. (sie nimmt die Maske ab: eine brave, gutmütige Frau wird sichtbar)

Toxilus (starrt sie interessiert an) „Mitleid“? Was ist das?

Matrosa (einfach) Du tust mir leid.

Toxilus (grimmig) Das freut mich!

Matrosa Ich weiss, Du findest keinen Schlaf, als hättest Du bittere Zahnschmerzen --

\begin{tabular}{|c|c|c|}
\hline 11 & $\ulcorner$ in $\rightarrow$ Villa $)\rceil]$ & in $[$ s Haus $)] \mid$ die Villa $) \mid$ \\
\hline 17 & $\ulcorner$ ZWEITER AKT $\urcorner]$ & ZWEITE[S]|R| [BILD] |AKT| \\
\hline 19 & $\ulcorner\overline{\urcorner}$ & $\overline{\text { [Wieder vor der Villa K.R. Thagos.] }}$ \\
\hline 36 & $\ulcorner$ Mitleid. $\urcorner]$ & [Gewissen.] |Mitleid.| \\
\hline
\end{tabular}


ToxiLus (fällt ihr ins Wort) Oeffne Lemniselenis Tür und es tut mir garantiert nichtsmehr weh!

Matrosa ${ }^{\ulcorner\urcorner}$Lieber mög Dich alles brennen --

Toxilus (grimmig) Wie freundlich!

5 Matrosa (ehrlich) Ich fühle mit Dir --

Toxilus (braust auf) Jetzt aber noch ein Wort und ich hau Dir eine auf Deinen Mund, dass Dir alle Deine gelben Zähne in Gänsemarsch hinten hinausmarschieren! Fahr ab!

(Stille)

10 Toxilus (drohend) Du bist noch da?

Matrosa (fährt ihn plötzlich an) Wenn Du das Mädel ehrlich liebst, dann darfst Du ihm nicht so den Kopf verdrehen! Was soll denn $\ulcorner$ diese Wichtigtuerei?! Die Ärmste $\urcorner$ wälzt sich $\ulcorner$ drinn $\urcorner$ herum --

ToxiLus (unterbricht sie) Wälzt sich?!

15 Matrosa Hin und her und auf und ab!

Toxilus Oh Götter! Sie wälzt sich!

Matrosa Auch sie kann nicht schlafen --

Toxilus Schweig, Furie!

Matrosa So nimm doch Vernunft an! Die Liebe ist allerdings ein Vesuv, der in einer

$20\left\lceil\right.$ Tur ${ }^{\urcorner}$ausbrechen möcht, aber ein Sklave hat kein Krater zu sein, sondern höchstens ein sanfter Hügel! Spar Deine Lava und beherrsch Dich! Du bringst ja noch eine brave Hetäre dazu, dass sie Dich wirklich liebt, ohne dass Du ihr was bieten kannst -- also das schlägt jedem Moralbegriff ins Gesicht, abgesehen davon, dass es der Kaiser feierlich verboten hat, dass sich ein $\ulcorner$ Sklav $\urcorner$ mit einer

25 Hetär --

\|Toxilus (unterbricht sie barsch) Schluss! Schluss! (bei Seite) Sie wälzt sich! (laut) $\ulcorner$ Geh und sag Deiner Herrin meinen lieblichsten Gruss -- ich, ich Toxilus, $\ulcorner$ würde $\urcorner$ sie freikaufen.

Matrosa Du?

30 Toxilus Ja. Bis morgen bring ich sechshundert Silberling -- tot oder lebendig. Sags ihr! $!^{7}$

Matrosa Nein, das sag ich ihr nicht. Ich werd mich schön hüten, einen solchen Blödsinn auszurichten!

ToxiLus Blödsinn?! Wenn $\ulcorner$ Toxilus sagt $\urcorner$, dass $\ulcorner e r\urcorner$ bis morgen sechshundert --

Matrosa (unterbricht ihn) Dass ich nicht wieher!

Toxilus Wieher nur, altes Pferd! Aber richt es aus!

Matrosa Fällt mir nicht ein!

Toxilus Du -- bring mich nicht zur Raserei!

Matrosa Halt Andere zum Narren, aber nicht uns, mich und meine ${ }^{\ulcorner}$sanfte ${ }^{\urcorner}$Herrin!

$\begin{array}{ll}3 & \ulcorner\urcorner] \\ 12-13 & \ulcorner\text { diese } \rightarrow \text { Ärmste }\urcorner \\ 13 & \ulcorner\text { drinn }\urcorner] \\ 20 & \ulcorner\text { Tur }\urcorner \\ 24 & \ulcorner\text { Sklav }\rceil \\ 27-31 & \ulcorner\text { Geh } \rightarrow \text { ihr! }\urcorner] \\ 27 & \ulcorner\text { würde }\urcorner] \\ 34 & \ulcorner\text { Toxilus sagt }\urcorner \\ 34 & \ulcorner\text { er }\urcorner \\ 39 & \ulcorner\text { sanfte }\urcorner\end{array}$

[Nein.]

[[das alles] |diese Wichtigtuerei|?! [Es] |Die Ärmste|] |diese $\rightarrow$ Ärmste| drinn[en] gemeint ist: Tour

Sklav[e]

Textentlehnung Plautus, PER ${ }^{12}$

$w[e]|\ddot{u}|$ rde

[ich] |Toxilus| sag[e]|t|

[ich] |er|

[ärmste] |sanfte| 
Toxilus Weib, sag ich Dir, richt es ihr aus -- sonst passiert noch ein Unglück! Ich kauf Deine $\ulcorner$ Sanfte $\urcorner$ frei, $\urcorner$ unter allen Umständen, in jeder Weise, auf jede Art -und wenn ich einen reichen Gauner $\ulcorner$ erschlagen $\urcorner$ und berauben müsst!

Matrosa Verblendet, verblendet! Du endest noch am Kreuz!

5 Toxilus $\ulcorner$ Scher $\urcorner$ Dich, Unke! Unk anderswo! Sonst häng ich Dich ins Meer hinein! Mit dem Kopf nach unten, damit Dich die Polypen kitzeln! Marsch-marsch!

Matrosa Ein ungehobelter Mensch! (rasch ab in die Villa)

Toxilus (allein; er fährt sich etwas erschöpft mit der Hand über die Augen und seufzt) Lemniselenis wälzt sich -- und ich steh da! `Achjaja, wer als Habenichts eindringt in die Pforten der Liebe, der überflügelt mit seiner Qual selbst die Qualen des Herkules. Lieber als mit Amor möcht ich mit der Hydra selber kämpfen -oder mit dem Eber aus Aetolien, den stymphalischen Vögeln, ja lieber sogar mit dem Riesen Antäus persönlich! So martere ich mein Gehirn: woher nimmst Du sechshundert Silberling? Und ich weiss doch im Voraus: die, die ich um einen Pump bitten könnt, die würden alle $\|$ nur sagen: „Ich habe selber nichts“ “- ${ }^{\text {(er hat }}$ sich gesetzt und vergräbt seinen Kopf in den Händen)

B AGNIO (ein davongelaufener Sklave, der auf die schiefe Ebene geraten ist, schleicht sich mit einem dickem Prügel bewaffnet, gefolgt von ZWEI KuMPANEN, die desgleichen adjustiert sind, von links an die Villa heran; unterdrückt) Da wären wir. Dort habt Ihr also besagte Villa -- Säulen, als wärs ein Tempel des Jupiter, derweil ist es nur der ländliche Lustsitz eines alten Wucherers, Erpressers, Wechsel- und Kontofälschers, Witwen- und Waisengeldbehälters! Das lebt sich, diese punische Banksau, Zinsenhengst von Caesars Gnaden -- (er herrscht den EINEN KumPanen an) Tritt auf keinen dürren Ast, sonst spring ich Dir auf den Nabel, miserabler Anfänger! Das Tor ist versperrt, wir treten durchs Fenster ein, und zwar durch das fünfte von links, ich kenn mich da aus, denn hier war ich zuhaus --

Hier lebt ich einst als armer Sklav

Fleissig, ehrlich, bieder, ${ }^{\urcorner}$brav Hab geschuftet Tag und Nacht

Bis ich habs herausgebracht:

Warum schuften, warum plagen

Warum an den Knochen nagen?

Machs doch, wie der Herre Dein

$\ulcorner$ Achte $\urcorner$ weder Sein noch Mein!

Nimm, was er den Sklaven nimmt

Und Dein ganzes Leben stimmt!

Alle DREi Nimm, was er den Sklaven nimmt

Und Dein ganzes Leben stimmt!

B AGnio Trara! Trara!

Die Einbrecher sind da!

Alle DREI Trara! Trara!

Die Einbrecher sind da!

\begin{tabular}{|c|c|c|}
\hline 2 & $\ulcorner$ Sanfte $\urcorner]$ & {$[$ Herrin $] \mid$ Sanfte $\mid$} \\
\hline 2 & $\ulcorner$ frei,,$\rceil]$ & frei\,/[--] \\
\hline 3 & $\ulcorner$ erschlagen $\urcorner]$ & [umbringen] lerschlagen| \\
\hline 5 & $\ulcorner$ Scher $\urcorner]$ & korrigiert aus: Scherr \\
\hline $9-1$ & $\ulcorner$ Achjaja $\rightarrow$ nichts““ -- ] & Textentlehnung Plautus, PER ${ }^{2}$ \\
\hline & $\begin{array}{l}\ulcorner\text { Fleissig } \rightarrow \text { bieder, }\urcorner \\
\ulcorner\text { Achte }\urcorner]\end{array}$ & $\begin{array}{l}\text { Fleissig } \backslash, / \text { ehrlich } \backslash, / \text { bieder } \backslash, / \\
\text { [Kenne] |Achte } \mid\end{array}$ \\
\hline
\end{tabular}


|| Toxilus (horcht auf) Wer murmelt denn da?

DIE DREI (erblicken erst jetzt TOXILUs und zucken zusammen)

TOXILUs (erblickt die DREI nicht) Sonderbar. Sollt ich schon Gespenster hören? Jaja, wenn die Liebe erwacht, sitzt man auf seinem Verstand -- (er lächelt wehmütig und grübelt wieder vor sich hin)

BAGNIO (sehr leise zu seinen KUMPANEN) $\left.{ }^{\ulcorner}\right\urcorner$Folget mir vorsichtig nach, Freunde! Ich werd mal jenem Burschen $\ulcorner$ dort $\urcorner$ ein bisserl den Kürbis spalten -- (er schleicht sich mit seinem dicken Prügel an ToxiLus heran)

Toxilus (erblickt nun B AGNIO und schnellt empor) Halt!

B AGNio (unterdrückt) Schrei nicht! Ich bin zu dritt und sags Dir im Guten, respektive im Bösen: ein lautes Wort und Du hörst den Zerberus bellen!

Toxilus (horcht auf) Wer seid Ihr?

BAGNIO Kindische Frage! Ein Dieb natürlich! Ein Aus- und Einbrecher, Haus-, Garten- und Strassenräuber, Gewalttäter, auch Totschläger, wenn Ihrs mal versuchen wolltet --

Toxilus (wie zuvor) Diese Stimme kenn ich doch, dieses rauhe Organ --

BAGNIO Mein Organ ist allerdings etwas heiser durch den übermässigen Genuss des Weines.

Toxilus Ist das nicht Bagnio?

B AGNio (perplex) Du kennst mich?

Toxilus Bagnio! Du möchst mich erschlagen? Mich?!

B AGNIO Ich pfleg mich nicht vorher zu erkundigen, wen ich hinterher erschlagen hab. Toxilus Ich bin Toxilus.

B AGNIO (hocherfreut und -überrascht) Was?! Toxilus?! Oh Jupiter Venus Apollo! Ist das aber eine Ueberraschung! Na, das hätt $\|$ mir aber itzo ehrlich leid getan, wenn ich Dir Deinen Kürbis demoliert hätt! (zu seinen KUMPanEN) ${ }^{\ulcorner}$Wisst Ihr, wer das ist? Das ist der einzige Sklav in meinem Leben, der mal ein Mitgefühl mit mir gehabt hat, wie man mich auf den Block gespannt hat, weil ich meine Mitsklaven bestohlen hab! Alle haben mich gehasst, nur er hat mich verteidigt -- das vergess ich Dir nimmer! $`$ Wie gehts, wie stehts, lieber guter alter Freund? Bist noch immer artig folgsam, ha?

Toxilus Ich fürchte-fürcht, bald werd ichs nimmer sein -- (er lächelt wieder wehmütig)

BAGNIO Anständig, sehr anständig!

ToxiLus Ich benötig nämlich dringendst Geld.

BAGNIO So fängts an! Wieviel?

Toxilus Sechshundert Silberling.

BAGNio Sechshundert? Respekt vor Deinem Appetit!

Toxilus Ich grübl schon die halbe Nacht, wer mir etwa $\ulcorner$ so viel $\urcorner$ leihen tät --

B AGNIO (fällt ihm ins Wort) Leihen? Dir? Was fällt Dir ein, unverschämter Kerl?!?

Toxilus Ich weiss, ich bin verwirrt -- Verzeih!

B AGNio Na also!

(Stille)

$\begin{array}{lll}6 & \ulcorner\urcorner] & \text { [Aufgepasst!] } \\ 7 & \ulcorner\text { dort }\urcorner] & \text { ldort/ } \\ 26 & \ulcorner\urcorner] & {[\text { Kommt herbei --] }} \\ 30-40 & \ulcorner\text { Wie } \rightarrow \text { Kerl?! }\urcorner] & \text { Textentlehnung Plautus, PER }{ }^{3} \text { und PER }{ }^{4} \\ 39 & \ulcorner\text { so viel }\urcorner] & \text { korrigiert aus: soviel }\end{array}$


Toxilus Drinnen im Haus ist eine Kasse.

B AGNIO Ich kann mich noch erinnern.

Toxilus Im dritten Zimmer.

B AGNIO Gleich rechterhand.

5 Toxilus Wenn man von links kommt.

B AGNIO (mit geschlossenen Augen) Ich seh sie noch vor mir.

(Stille)

\| Toxilus Man kann auch durchs Fenster.

ÖLA 3/W 109

B Agnio Stimmt. Durchs fünfte von links.

BS 30 a, BI. 23

10 Toxilus Nein. Dort schläft heut wer. Durchs vierte von rechts.

B AGnio Aha.

(Stille)

Toxilus Die Herrschaft ist verreist.

Bagnio Ehschonwissen! Drum bin ich ja da.

15 Toxilus Aha.

(Stille)

B AGnIO Was ist denn in der Kasse?

Toxilus Neunhundert Silberling.

B AGNIO (fasst sich ans Herz) Sags nochmal!

20 Toxilus Neunhundert.

B AGnIO Wie das klingt! Neun-hun-dert! -- das ${ }^{\ulcorner}$zerrinnt $\urcorner^{7}$ auf der Zunge, wie Butter -(Stille)

Toxilus (plötzlich entschlossen) Wenn du mir sechshundert abgibst, garantier ich Dir, dass Dich niemand entdeckt.

BAGNio Lieb von Dir. Zwar hab ich keine Angst, entdeckt zu werden, denn es ist noch keine neue Strafe ersonnen worden, an die ich mich nicht schon gewöhnt hätt -- `jedoch: $\urcorner$ gemacht! Du kriegst Deine sechshundert -- (zu seinen KumPANEN) Aufgehts, los! Durchs fünfte Fenster von links --

Toxilus (fällt ihm ins $\left\ulcorner\right.$ Wort ${ }^{\top}$ ) Aber-aber! Durchs vierte von rechts!

B AGNIO (herrscht ihn an) Verzweifel nur nicht gleich, wenn sich mal einer verspricht! Uebrigens: was machst Du eigentlich mit ${ }^{\ulcorner}$so viel $\urcorner$Geld? Willst Du fliehen?

Toxilus Nein. Ich möchte jemand freikaufen.

B AGNIO Freikaufen? Wer ist denn heutzutag noch $\ulcorner$ so viel $\urcorner$ wert!

Toxilus Die, die ich meine, wäre sechstausend wert und es wär immer noch zu 35 wenig.

|| B AGNio (begreift voll Verachtung) Ach, ein Weib --

$\ulcorner$ Toxilus Amor hat mein Herz durchbohrt.

B AGNIO ( $($ stutz $t\urcorner)$ Wer? Ja, lieben denn Sklaven auch?

Toxilus Was tun? Den Göttern trotzen? Bin ich ein Titane?

Bagnio Du bist ein Tepp. Aber verlass Dich auf mich -- (zu seinen Kumpanen) Mir nach! (ab mit ihnen hinter die Villa)

$\begin{array}{lll}21 & \ulcorner\text { zerrinnt }\urcorner] & \text { korrigiert aus: zerrint } \\ 27 & \ulcorner\text { jedoch: }\urcorner \text { }] & \text { jedoch }: / / \\ 29 & \ulcorner\text { Wort }\urcorner] & W[\ddot{o}]|o| r t \\ 31 & \ulcorner\text { so viel }\urcorner] & \text { korrigiert aus: soviel } \\ 33 & \ulcorner\text { so viel }\urcorner] & \text { korrigiert aus: soviel } \\ 37-39 & \ulcorner\text { Toxilus } \rightarrow \text { Titane? }\urcorner] & \text { Textentlehnung Plautus, PER }{ }^{3} \\ 38 & \ulcorner\text { stutz } t\urcorner] & s \backslash t / u t z t\end{array}$


LEMNISELENIS (tritt im Nachtgewand aus der Villa, sieht sich um, erblickt ToxiLus, nähert sich ihm unhörbar und hält ihm plötzlich von hinten mit beiden Händen die Augen zu; leise) Wer bin ich?

Toxilus (erschrickt und reisst sich los) Wer da?! Ach -- (er starrt sie entgeistert an) 5 Lemniselenis (lächelt) Dreimal darfst Du raten --

Toxilus (nähert sich ihr langsam und reisst sie plötzlich stürmisch an sich)

LEMNISELENIS Nicht so laut! (sie lässt sich von ihm umarmen, umarmt ihn, und Beide küssen sich; dann löst sie sich langsam los) Die brave Matrosa schläft --

ToxILus Endlich!

10 Lemniselenis Ich hab ihr in ihren Erfrischungstee mein stärkstes Pülverchen hineingeschmuggelt -- jetzt ${ }^{\ulcorner}$schnarcht ${ }^{\urcorner}$sie, dass $\ulcorner$die Betten zittern .

ToxiLus Hoffentlich $\ulcorner$ zittern sie lang!

LEMNISELENIS (traurig) Wer weiss! (sie blickt zum Himmel empor)

Oh Venus!

15 Steinig und steil sind die Strassen der liebenden Herzen

Denen die Götter die Freiheit der Küsse nicht gönnen.

Arm ist das Mädchen, das heimlich sich fortschleichen muss

Angstvoll zu leeren den Becher der hastigen Lust.

Arm ist das Mädchen, das in fremde Gedanken verstrickt Zwischen zwei Türen, furchtsam bei jedem Geknarre $\ulcorner$ erschrickt.

Wie gern wär ich $\ulcorner$ unbewacht $\urcorner,\ulcorner$ gekettet an Dich $\urcorner$ allein

Hinter verriegelten Fenstern und Türen im eigenem Heim.

Toxilus Ach, Lemniselenis --

Ich finde keine Worte, nur Deinen Namen.

25 || Lemniselenis Oh, jetzt gehts mir gut! Plötzlich bin ich reich. Was gehört mir nicht alles! Das Meer und die Luft, die Wolken, der Mond und die silbernen Farben der Nacht! Das alles hast Du mir geschenkt. Ich danke Dir.

ToxiLus Dank mir nicht, sonst bricht mir das $\left\ulcorner\right.$ Herz - ${ }^{\urcorner}$

Lemniselenis Wenn man nur keinen Kopf hätte!

30 Toxilus Sei so gut!

LEMNISELENIS Wenn man nur nicht denken müsst -- denn was wird schon morgen sein? Morgen schon wird gesungen: „Schmücke Dich, Mädchen, schmücke Dich, es kommt der Sklavenhändler" --

Toxilus Also den lass ruhig kommen.

LEMNISELENIS Wie einfach Du das sagst --

ToxiLus Ich sag es einfach, weil es einfach ist. Du wirst nämlich morgen einfach frei.

Ich kauf Dich frei -- ganz einfach!

LEMniselenis Du? Woher willst denn Du Dir das viele Geld `hernehmen?!

Toxilus Ein Freund wirds mir beschaffen, er gab mir sein Wort.

40 Lemniselenis Was ist das für ein Freund?

ToxiLus Ein alter Bekannter. Ein verlässlicher Mensch.

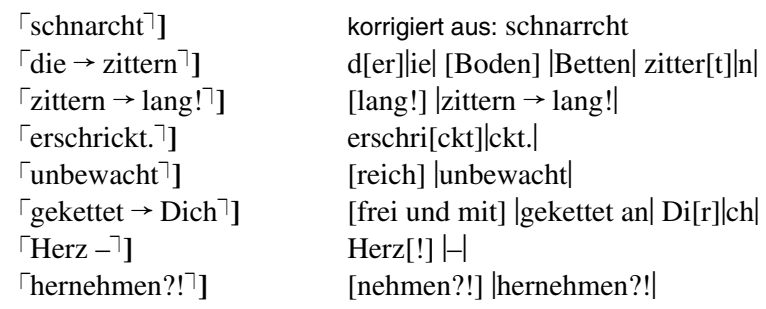


LEMNISELENIS Und der hat ${ }^{\ulcorner}$so viel $\urcorner$Geld?

Toxilus Er hat. Beruhig Dich, er hat.

LEMNISELENIS Ist er denn so reich?

Toxilus Reich ist garkein Ausdruck! Wenn er will, gehört ihm die ganze Welt, er muss nur zugreifen -- (er macht die Geste des Stehlens)

Lemniselenis Jetzt hab ich Angst.

Toxilus Warum, Liebste?

LEMNISELENIS Du -- Du wirst doch nicht stehlen?

Toxilus Ich? Was denkst Du von mir? Warum nicht?

10 Lemniselenis (entsetzt) Nein!

Toxilus Für Dich: ja!

\| Lemniselenis $\ulcorner$ (wie zuvor) Nein, nicht für mich, nie! Versprich es mir, dass Du mich lieber nicht freikaufst, als dass Du mich auf verbrecherische Art erwirbst -- versprich es mir, bitte-bitte! Ich bin doch besorgt um Dein leibliches Wohl, man wird

15 Dich $\ulcorner$ noch $\urcorner$ vierteilen!

Toxilus (fixiert sie) Liebst Du mich?

LEMNISELENIS Ja, aber --

ToxiLus (unterbricht sie) Dann lass mich stehlen!

(Stille)

20 Lemniselenis Oh Götter, ahnt ich es doch!

Toxilus Höre: in meinen Augen gibt es nur ein Verbrechen: Dich weiter im Joche der Sklaverei zu belassen, Dich wieder weiterzuverkaufen, zu verschachern, zu vertrödeln, wie ein lebloses Ding -- Heut ${ }^{\ulcorner}$kenne $^{\urcorner}$ich nur dieses einzige Verbrechen und sonst sei mir alles Recht!

LEMNISELENIS Wenn mein Verkauf ein Verbrechen ist, dann ist doch auch jeder Verkauf eines Menschen --

Toxilus (fällt ihr ins Wort) Ist er auch, ist er auch! Alles Verbrechen, lauter Verbrechen! Man hat uns alle gestohlen, alle-alle!

LEMNiSELENIS Nicht so laut! (sie sieht sich ängstlich um)

30 Toxilus Dann sag ichs leise: Du wirst noch sehen, wir stehlen uns alle zurück, alle! (Stille)

Lemniselenis Hast Du gehört, dass es einen neuen Gott geben soll?

Toxilus Einen neuen Gott?

LEMNISELENIS Ja. Er soll unsichtbar sein.

35 Toxilus Unsichtbar?

LEMNISELENIS Er soll immer um einen herum sein -- um einen jeden von uns, denn er sagt, dass alle Menschen gleich sind --

Toxilus Wo hast Du das gehört?

LEMNiselenis Matrosa hats mir erzählt. Sie war mal da, wo sich die Leut treffen, die zu dem neuem Gott gehören -- sie kommen unter der Erde zusammen.

Toxilus Was machen sie denn dort?

Lemniselenis Sie singen. Ueberall unter der Erde -- halb Rom soll schon ganz unterhöhlt sein.

(Stille)

\begin{tabular}{rll}
\hline & & \\
1 & $\ulcorner$ so viel $\urcorner]$ & korrigiert aus: soviel \\
12 & $\ulcorner($ wie $\rightarrow$ nie $!]$ & {$[$ Nein! $]$ (wie $\rightarrow$ nie! } \\
15 & $\ulcorner$ noch $\urcorner]$ & Inoch/ \\
23 & $\ulcorner$ kenne $\urcorner]$ & kennle/
\end{tabular}


|| Toxilus Man hört immer wieder von neuen Göttern, man weiss schon garnichtmehr, was man glauben soll. Ich glaube nur, dass ich Dich wirklich liebe --

Matrosa (schreit in der Villa auf und stürzt heraus) Hilfe! Hilfe! Hilfe! Einbrecher, Räuber, Mörder!

5 Lemniselenis Um der Himmel Willen!

Toxilus (ist erschrocken, fasste sich jedoch rasch und herrscht nun MATROSA an) Was plärrst Du da und weckst das Haus?! Hier gibts doch keine Räuber und Mörder -- die hätt ich doch sehen müssen, wo ich die ganze Weil heraussen steh! Du hast geträumt!

Matrosa Und dieser blaue Fleck da?! Hab ich den etwa auch nur geträumt?! Mit einem Prügel hat mich der Schurke über den Schädel geschlagen --

Toxilus (unterbricht sie) Du wirst Dich im Traum selber über Deinen Schädel --

Matrosa (erblickt erst jetzt Lemniselenis und unterbricht Toxilus) Was seh ich?! Und das Mädel hier ist vielleicht auch nur ein Traum?! ( $z u$ LEMNISELENIS) Hinein mit Euch!

LeMniselenis (herrscht sie an) Du hast mir nichts zu befehlen, Du bist meine Dienerin, merk Dir das endlich!

Matrosa Die Dienerin einer Hetäre ist wie die Mutter einer freien Frau! Ich weiss, wenn Ihr verkauft werdet, gelte ich nur als $\ulcorner$ Zuwag $\urcorner$, aber trotzdem bin ich Euer schützender Geist!

Toxilus ( $z u$ Matrosa) Fahr ab!

Lemniselenis Morgen werd ich frei!

Toxilus (schielt nach der Villa) Hoffentlich --

Matrosa Lächerlich! Schwätzt nicht, Herrin!

LEMNISELENIS Ich schwätze nicht! (sie fasst sich plötzlich ans Herz) Oh, jetzt fühl ichs so stark, dies brennende Weh: man $\|$ liebt nur einmal im Leben -- -- Amor, Amor!

Matrosa (blickt zum Himmel empor, sieht nichts und macht eine wegwerfende Geste) Ich möcht nicht wissen, wie oft Ihr noch lieben werdet mit Eueren lumpigen achtzehn Jahren!

LEMNISELENIS (traurig) Ich lebe nicht lang.

Matrosa Jetzt das auch noch!

Aufseher (kommt rasch von links) Hallo, Ihr seid hier alle $\ulcorner$ vor dem Tor $\urcorner$ ?! Mitten in der $\ulcorner$ Nacht?! $\urcorner$ Was gibts denn?!

35 Toxilus Nichts. Wir können nur alle nicht schlafen.

Aufsener Komisch. Ich komm grad aus Pompeji vom Dordalus, der alte ${ }^{\ulcorner}$Schäbige $\urcorner$ wird sich das Fräulein morgen in aller Früh abholen -- er bringt auch gleich ein paar Kunden mit, mir scheint, aus Britannien!

Toxilus ( $z u$ Lemniselenis) Verlass Dich auf mich --

LEMNiselenis Ja.

Paegnium (stürzt aus der Villa) Toxilus, Toxilus! Die Kasse ist geplündert! Geplündert!

Aufseher Was?! Die Kasse?!

gemeint ist: Zuwaage [heraussen] |vor $\rightarrow$ Tor| Nacht?!!/ korrigiert aus: Schäbbige
ÖLA 3/W $109-$ BS 30 a, Bl. 28 
PaEgnium Drei warens, drei Verbrecher! Ich hab sie deutlich gesehen! Kommt schnell, schnell -- vielleicht erwischt Ihr sie noch!

Aufseher Ich dreh ihnen die Hälse um! (rasch ab mit PAegnium in die Villa)

Matrosa ( $z u$ Toxilus) Na, hab ich geträumt?

5 Toxilus Nein. Den Göttern sei Dank --

Matrosa (horcht auf) Was murmelst Du da?

Toxilus Nichts.

Matrosa (blickt ihn misstrauisch an; $z u$ Lemniselenis) Kommt!

LEMNISELENIS Nein.

10 Matrosa (zuckt die Schultern und ab in die Villa)

\| ToxiLus (lauscht in die Nacht)

LEMNISELENIS Sind sie entkommen?

ÖLA 3/W $109-$ BS 30 a, BI. 29

Toxilus (wie zuvor) Wenn sich nichts rührt, dann ja --

(Stille)

15 LEMNiselenis Ich höre nichts.

Toxilus Ich auch nichts -- (er legt seinen Arm um ihre Schultern und blickt zum Himmel empor)

$\ulcorner$ Oh Jupiter, allmächtiger, hehrer Sohn der Rhea

Höchster Gott!

20 Aus dessen Händen Reichtum, Hoffnung, Heil entströmt

Aus tiefstem Herzen bringe ich Dir Opfer dar

Weil hilfreich Du dem Freund zur Flucht verhalfst

Weil freundlich Du dem Freund Gelegenheit gabst

Mir den allergrössten Dienst zu tun:

25

Gestohlenes Geld zu bringen in Geldesnot.

Lemniselenis!

Morgen bist Du frei!

(Vorhang)

\section{|| DRITTER AKT}

Am nächsten Morgen. Wieder scheint die Sonne, doch diesmal wie durch Nebel, trotz des blauen Himmels. Die SKLAVEN und die SKLAVINNEN sitzen vor der Villa und frühstücken. Matrosa, mit einem Verband um den Kopf, Paegnium und der Aufseher sind auch dabei.

40

Aufseher ( $z u$ Paegnium) Du hättest ihm ein Bein stellen sollen, zimperlicher Bursche!

Paegnium Ich?

Aufseher Jawohl, Du! Mit Einbrechern muss man deutlich ‘dischkurieren?! Bein 45 stellen und schon drauf, Daumen in die Augen, Knie auf die Brust, Knöchel ver-

\footnotetext{
18-25 「Oh $\rightarrow$ Geldesnot. $\urcorner \quad$ Textentlehnung Plautus, PER ${ }^{8}$

$44\lceil$ dischkurieren $\urcorner$ gemeint ist: diskurieren
} 
drehen, Arm auskegeln, Tritt übers Schienbein und ein Schlag mit der Kante der äusseren Handfläche nach der Gurgelgegend -- das hätt sich gehört! Aber nicht weglaufen mit Hilfegeplärr! Dann hätten wir jetzt diese Wegelagerer und das Geld in der Kasse wär gerettet!

5 Matrosa Du redest Dich leicht mit Deiner Muskulatur! Aber dies schmächtige Bürscherl hätts mit einem solchem Halunken aufnehmen sollen?! Du hättest den sehen $\ulcorner$ sollen $\urcorner$, der mir eine über den Schädel gehaut hat -- breit wie ein Bär und stark wie ein Ochs!

PAEgniUm Und ausserdem warens zu dritt!

10 || Aufseher Zu dritt-zu dritt! Wie ich in Deinem Alter war, $\ulcorner$ hab $\urcorner$ ichs mal mit sechs allein aufgenommen -- mit sechs Riesen, die kleinere Bäum mit der linken Hand samt den Wurzeln aus der Erde gerissen haben, und zwar aus einem steinigem BS 30 a, BI. 31 Boden --

Matrosa (unterbricht ihn) Nanana! 'Du ${ }^{\top}$ renommierst schon manchmal, wie unser $15 \quad$ Herr Gloriosus!

Aufseher (herrscht Matrosa an) Vergleich mich nicht mit dem ${ }^{\ulcorner}$Trottel, ja?!

Die SkLAVEN (lachen)

Aufseher (herrscht die Sklaven an) Ruhe! Lacht nicht! Kuscht und `fresst?!

EIN SKLAVE Kusch selber und friss!

20 AUfSEHER (schnellt empor) Was?!

Der Sklave Vergiss es nur ja nicht, dass Du keine Peitschen mehr hast! Freu Dich lieber, dass wirs vergessen, dass Du mal eine gehabt hast! Glotz nicht so blöd, sonst schütt ich Dir meine Suppe ins Gesicht!

AufseHER (überaus perplex) Was sagt man!

25 Paegnium Kusch und friss.

「Aufseher Wie bitte?! Das wagst Du? Mir? Dem älteren Manne?!

$\ulcorner$ Paegnium Du bist ein Sklav, genau wie ich.

Aufseher So? Na pass nur auf, was ich Dir geben werde --

PAEgnium (wird immer frecher) Nichts. Du hast ja nichts.

30 Aufseher Mich sollen doch alle Götter strafen --

PAEgnium (fällt ihm ins Wort) Das wünsch ich Dir auch als guter Freund.

AufseHER Jetzt steht die Welt nimmer lang!

Eine SkLavin (schrill) Hoffentlich! Hoffentlich geht bald alles unter!

(Stille)

35 Paegnium Apropos untergehen: wo unsere Herrschaft jetzt wohl segeln mag?

|| Matrosa Segeln wird sie kaum, denn es weht ja nicht das geringste Lüftchen --

EIN SKLAVE Es ist schwül, als käm ein Wetter.

PAEgnium Ich seh noch keine Wolke --

Eine Sklavin Oh, das geht rasch!

Aufseher Ohne Wind wird nur gerudert, gerudert.

$\begin{array}{cll}7 & \ulcorner\text { sollen }\urcorner] & \text { korrigiert aus: sóllen } \\ 10 & \ulcorner\mathrm{hab}\urcorner] & \text { korrigiert aus: habs } \\ 14 & \ulcorner\mathrm{Du}\urcorner] & \operatorname{Du}[\{\}] \\ 16 & \ulcorner\urcorner] & {[\text { eitlen }]} \\ 18 & \ulcorner\text { fresst }\urcorner] & \text { fr[i]le|sst } \\ 26 & \ulcorner\text { AUFSEHER } \rightarrow \text { Manne?! }\urcorner] & \text { Textentlehnung Plautus, PER }{ }^{10} \\ 27-31 & \ulcorner\text { PAEGNIUM } \rightarrow \text { Freund. }\urcorner] & \text { Textentlehnung Plautus, PER }{ }^{11}\end{array}$


Die Sklaven (singen)

Bet und ruder! ruft die Welt

Bete kurz, denn Zeit ist Geld!

An die Kette pocht der Tod

Bete kurz, denn Zeit ist Brot!

Und Du ackerst und Du säst

Und Du nietest und Du nähst

Und Du hämmerst und Du spinnst

10

Sag, oh Sklav, was Du gewinnst!

Wirkst am Webstuhl Tag und Nacht

Schürfst im Erz- und Kohlenschacht

Füllst des Ueberflusses Horn

Füllst es hoch mit Wein und Korn.

Alles ist Dein Werk! oh sprich

Alles, aber nichts für Dich!

Und von allem nur allein

Die Du schmiedst, die Kette, Dein --

Was Ihr hebt ans Sonnenlicht

Schätze sind es für den Wicht

Was Ihr kleidet und beschuht

Tritt auf Euch voll Uebermut.

\| Bet und ruder! ruft die Welt

Bete kurz, denn Zeit ist Geld!

An die Kette pocht der Tod

Bete kurz, denn Zeit ist Brot -- --

Aufseher ( $z u$ Matrosa) Wieviel war denn eigentlich in der Kasse?

Matrosa (in Gedanken) In was für einer Kasse?

AufseHER Na in unserer Kasse, die gestern geplündert worden ist!

Matrosa Ahso! Keine Ahnung --

35 Paegnium Das weiss nur Toxilus persönlich, denn er hat die Schlüssel zur Kasse.

Matrosa (horcht unwillkürlich auf) Toxilus? Soso.

Aufseher (horcht auf; zu Matrosa) Was heisst das? Dieses eigentümliche „soso“?

Matrosa Nur so.

(Stille)

40 Aufseher Du willst doch damit nicht soso etwa ausdrücken, dass unser allseits verehrter Freund Toxilus soso die Finger im Spiel dabei --

Matrosa (fällt ihm ins Wort) Ich will nichts gesagt haben!

Aufseher Soso. (er braust plötzlich auf) Aber das wär ja allerhand!

Paegnium Natürlich hat er seine Finger dabei.

45 Matrosa Was redest Du da?! Schämst Du Dich nicht?!

PaEgnium Ich weiss Bescheid.

Matrosa Nichts weisst Du, nichts, Lausbub, verteufelter!

Aufseher ( $z u$ Matrosa) Ich versteh Deine eigentümliche Aufregung nicht -- 
Matrosa (fällt ihm ins Wort) Ich kann es nicht leiden, dass jemand beschuldigt wird ohne zwingende Beweise -- oh, ich kenn das selber! Wie oft hat man mich schon verleumdet!

Aufseher (schreit) Also was ist los?! Hat er die Finger im Spiel -- ja oder nein?!

5 || PAEgnium Ich hab ihn nämlich zuvor belauscht, bei Lemniselenis --

Matrosa (unterbricht ihn) Was?! Er steckt schon wieder bei ihr?!

ÖLA 3/W 109 BS 30 a, BI. 34

PAEgNiUm Er steckt noch immer bei ihr!

Matrosa Skandal! $\left\ulcorner\mathrm{Na},{ }^{\urcorner}\right.$lang dauerts nimmer, der Dordalus muss ja jeden Moment erscheinen --

AufseHer (unterbricht sie brüllend) Dordalus hin und her! Was ist also mit seinen Fingern?!

Paegnium Sie stecken drinn! Er hat das Geld!

Alle Sklaven (die interessiert nähergetreten waren) Das Geld?!

Paegnium Toxilus hat das Geld!

AufseHER (schnappt ausser sich nach Luft) Mich trifft der Schlag -- (er muss sich setzen)

Paegnium ( $z u$ den SkLAVEN) Grad hat er es seiner Lemniselenis erzählt, wie sich der Oberdieb wiederhergeschlichen, knapp vor Sonnenaufgang, und wie ihm der Gauner das Geld abgezählt überreicht hat -- sechshundert Silberlinge!

20 AUfSEHER (schnellt wieder empor) Wieviel?!

Alle Sklaven Sechshundert?!

PAEgnium Ja.

(Stille)

Aufseher ( $z$ u den erstarrten Sklaven) Hört Ihr das? Hört Ihr es, wie sich Euer Toxilus benimmt -- Euer Abgott, Euer Wohltäter, Euer Götterliebling?! Wenn Ihr müde von des Tages Last im Keller ruht, räubert er die Kasse aus, aber wenn die Herrschaft zurückkommt, kriegt Ihr die Prügel, Ihr, inclusive mir, weil hier eingebrochen worden ist -- aber diese Prügel sind Euch vielleicht am End noch wurscht, Ihr Haus- und Hofteppen, Ihr seid es ja im Stand und kümmert Euch nur um die Prügel, die ich austeil! Was sagt Ihr nun zu Toxilus?!

Alle SkLAVEn (nehmen langsam, fast feierlich, ihre Masken ab: alle Leidenschaften werden sichtbar; im Sprechchor)

Wir alle, jeder und jede, hätten das Geld auch genommen

Wenn uns die Gnade der Götter hätt einen Weg gewiesen

35 Um ohne Gefahr und frei von lästiger Störung

Die Kasse der Herrschaft zu plündern.

Wir alle

Hätten so gerne gestohlen

\| Ohne an die Unbill der Unschuld zu denken.

Doch in diesem Falle

Wo von der Missetat keiner und keine von uns etwas hat

Holen wir uns den Missetäter, ihn zu verprügeln nach Noten!

Aufseher Nach Noten!

Alle (ausser Matrosa) Toxilus! Toxilus!

LEMNISELENIS (tritt rasch aus der Villa) Ihr ruft seinen Namen?! Er schläft grad und träumt -- oh still, wecket ihn nicht auf!

$8 \quad\ulcorner\mathrm{Na}\urcorner,] \quad \quad \mathrm{Na}, /$


AUFSEHER (lacht höhnisch hellauf)

LEMNISELENIS Nicht doch, nicht so laut! (sie blickt nach der Villa) Reisst ihn \ulcorner\urcorner nicht aus Morpheus Armen --

AufseHER Moment! (er entledigt sich seiner Jacke und krempelt die Aermel hoch -und auch ALLE SKLAVEN tun desgleichen, soweit sie welche haben)

LeMniselenis (ahnt Unheil, sehr besorgt) Um aller Götter Willen -- was wollt Ihr von meinem Mann?

AufseHer (herrscht sie an) Her mit dem Geld! Wir sind im Bilde und wissen alles!

Alle Sklaven Alles! Alles!

10 Aufseher Her mit den sechshundert Silberling und zurück damit in die Kasse!

Alle Sklaven Oh Freund, nicht in die Kasse gebe der Mann das Geld zurück

Das Geld, das er durch frevle Tat in tiefer Nacht sich erworben

Lieber verteile er es unter uns, wenn er es eh schon besitzt

Damit auch wir uns an seinem Verbrechen erfreuen!

15 Aufseher Ah da schau her!

|| Toxilus (der während der SKLAVEN Chor verschlafen und gähnend aus der Villa trat, dann die Ohren spitzte, ruft nun plötzlich) Nur auf ein Wort, oh Freunde!

AlLE (bemerken ihn erst jetzt; drohend) Toxilus!

Toxilus Mitsklaven! Wie rührt mich zu innerst $\left\ulcorner\right.$ unser ${ }^{\urcorner}$Schicksal

$\ulcorner$ Das $\urcorner$ mich mit allen Fasern der Seele an Euch kettet --

(er muss gähnen)

Hier steht Ihr nun vor mir

Söhne und Töchter aus allen Teilen der Welt

Und wollt mit mir teilen das Geld

Das ich gestohlen --

(er muss wieder gähnen)

Die SkLaven (werden angesteckt und müssen auch gähnen)

Aufseher ( $z$ u den Sklaven) Gähnt nicht! Er wickelt Euch ein!

ToxILus Ich wickle nicht! Weder Euch ein, noch mich heraus! Beim Jupiter, das hat ein Toxilus nicht nötig! Kennt Ihr mich denn nichtmehr, mich, Eueren Freund -habt Ihr es denn vergessen, wie oft ich Euch beschützte vor Hoffart, Wut und Uebermut unserer Herrschaft?! Und -- (er deutet auf den AUfSEHER) vor jenem! Hab denn nicht ich ihm erst gestern seine Peitsche genommen -- ja oder nein?!

Aufsener Jawohl! Damit ich Dir nicht auf die Finger klopfen kann, wenn Du die Kasse öffnest!

\| Alle Sklaven (zum Aufseher) Gib Ruh! Gib Ruh! (sie gähnen)

Toxilus Ihr alle, jeder und jede, habt schon mal „Danke“ zu mir gesagt -- „Danke!“ für irgendeinen, grossen oder kleinen, Dienst. Aber heute, Freunde, lasst auch mich mal danken dürfen -- Euch danken! Gewährt mir die Bitte, erlaubt es mir, seid so gut --

Die Sklaven (krempeln die Aermel wieder herab)

Toxilus (lächelt leise) Gewiss, wer würds nicht verstehen, wenn Ihr mich steinigen wolltet, denn ich hab ja sechshundert Silberling in der Tasche! Und Ihr denkt, ich hätte an Euere Buckel nicht gedacht, nicht an die Prügel, die Ihr für mein Geld

$\begin{array}{rll}2 & \ulcorner\urcorner] & {[\text { doch] }} \\ 19 & \ulcorner\text { unser }\urcorner] & \text { [Euer] lunser } \\ 20 & \ulcorner\text { Das }\urcorner] & \text { korrigiert aus: Dass }\end{array}$


kassiert -- oh Irrtum! Natürlich hab ich mit Euerer Unschuld gerungen, und hab es aber trotzdem gestohlen!

AUFSEHER Er brüstet sich noch! (er muss plötzlich heftig gähnen)

Toxilus (zum Aufseher) Gähne nicht, wenn sich ein braver Mann vor braven Menschen verteidigt!

Alle Sklaven Heil Toxilus! Heil!

Toxilus ( $z$ u den SkLaven) Lange hab ich alles erwogen und hielt eine Waage in der Hand. Dann warf ich meine ${ }^{\ulcorner}$Ehrlichkeit ${ }^{\urcorner}$und Euere Buckel in die eine $\left\ulcorner\right.$Schale ${ }^{\urcorner}$ und in die andere legte ich säuberlich die Silberling -- und siehe! Die Silberlinge wogen $\ulcorner$ schwerer $\urcorner$ ! Ganz droben, fast unsichtbar hoch, hingen Euere Buckel und meine Ehrlichkeit -- und ganz tief herunten das Geld. Aber es wog nur deshalb so schwer, weil || ich es nicht für mich geraubt, sondern für eine Sklavin, die ich freikaufen möchte. Es geht um Eueresgleichen! Helft mir! das ist meine Bitte an Euch. Rettet sie! das sei Euer Dank an mich. Kauft sie frei -- Lemniselenis!

Eine Sklavin Was, die?! Das nennst Du eine Sklavin?! Das wär mir eine feine Sklavin -- nichts arbeiten, nur auf seidenen Kissen herumlümmeln und sich parfümieren! Für sowas soll ich meinen Buckel hinhalten?! Nein, nie-nie! Kauf eine $\ulcorner$ hässliche ${ }^{\urcorner}$frei, eine arme Sklavin, aber keine Reiche!

Lemniselenis Oh Schwester! Was weisst Du von der reichen Sklaven Leid! Ich liege auf Kissen und Pölstern -- doch mein Herz liegt auf Stein. Was weisst Du von der armen Schönheit Kummer? Wie schwer ist es Liebe zu geben für Lohn --

Die SkLavin Lüg nicht! Lieben ist leichter, als arbeiten!

Ein Sklave (zur Sklavin) Sei so gut!

Die Sklavin Lass mich, Mann! ( $z u$ Lemniselenis) Hochmütige Gans!

LemNiselenis Du hast recht, wenn Du mich beschimpfst -- und doch nicht recht. Ja, ich lüge fast immer, aber diesmal lüge ich nicht, so wahr es einen Jupiter gibt, eine Venus und einen Phöbus $\ulcorner$ Apollon $\urcorner$ ! Es war nicht Hochmut, dass ich wegsah, wenn ich an Euch vorbeiging -- es war Angst, Angst vor Eueren Augen. Aber jetzt seh ich Euch alle an und möchte keinen von Euch vergessen, möchte immer schauen in der Armut Gesicht -- und wenn Ihr mich jetzt freikauft, dann will ich es vor allen Göttern versprechen, dass ich immer für Euch sorgen werde! Betrachtet mich als Euer Schwert! Schickt mich als freien Menschen unter unsere freien Feinde hinein! Ich mähe sie alle nieder -- jeden und jede, die mir begegnen! Ihr braucht nur zu befehlen und ich hol mir die Seuche, die Euch am bekömmlichsten dünkt, um unsere Feinde auszurotten -- ich möchte sie alle ausrotten und als Letzte dann mich selbst, als die letzte Freie! Nicht mitzulieben, mitzuhassen bin ich da! ‘( sie umarmt Toxilus)

Alle Sklaven Heil Lemniselenis! Heil!

Wir kaufen Dich frei! Wir kaufen Dich frei!

Mit dem Pfeil dem Bogen

Kommt der Schütz gezogen!

Ueber Berg und Tal

\begin{tabular}{|c|c|c|}
\hline 8 & $\ulcorner$ Ehrlichkeit $\urcorner]$ & [Gefahr] |Ehrlichkeit| \\
\hline 8 & $\ulcorner$ Schale $\urcorner]$ & korrigiert aus: Schaale \\
\hline 10 & $\lceil$ schwerer $\rceil]$ & schwe[er]|r|er \\
\hline $7-18$ & $\lceil$ hässliche $\rceil]$ & {$[\mathrm{H}]|h| a ̈ s s l i c h e$} \\
\hline & $\ulcorner$ Apollon $\rceil$ & korrigiert aus: App \\
\hline 37 & $\ulcorner($ sie $\rightarrow$ Toxilus $)\urcorner]$ & $\rightarrow$ Toxilus $) /$ \\
\hline
\end{tabular}


Rauscht der Wasserfall!

Heil! Heil! Heil!

Ein Wort ist ein Pfeil!

Toxilus (unterbricht die Sklaven) Halt! Warum solch sinnlos Reden, Freunde?!

$5 \quad$ Warum berauscht Ihr Euch am Wort? Denkt doch lieber, denkt!

Alle Sklaven (horchen auf) Denken? (sie sehen sich gegenseitig an und denken dann, jeder für sich)

(Stille)

Toxilus Nun?

10 Alle Sklaven Wir denken, doch es kommt nichts dabei heraus. Wir denken, es müsst uns wer was sagen. Wir denken, dass wir warten.

Toxilus (mit leiser Ironie) Auf was warten wir denn?

Matrosa (plötzlich) \ulcorner\urcorner Toxilus! Was geschieht denn eigentlich mit mir, wenn Lemniselenis frei wird?

Toxilus Mit Dir? Da Du gewissermassen nur die $\ulcorner$ Zuwag $\urcorner$ bist -- wirst mit ihr gekauft und verkauft und wirst also auch mit ihr frei!

Matrosa (überglücklich) Frei?! Ich auch?!

Toxilus Logisch!

Matrosa Frei! Oh grosser Gott im Himmel -- nein, $\ulcorner$ dass $\urcorner$ ich das noch durft erleben! Achtundfünfzig Jahre bin ich nun gefangen und plötzlich frei, frei -- wie dank ich Dir, mein lieber Gott! (sie sinkt in die Kniee, bekreuzigt sich, betet unhörbar, bekreuzigt sich wieder und steht auf)

AlLE (sahen ihr verblüfft $z u$ )

Aufseher ( $z u$ Matrosa) Was hast denn jetzt getan?

25 Matrosa Ich habe gebetet.

Toxilus Gebetet? Seit wann betet man denn so?

\| Matrosa Zu meinem Gott betet man so.

Aufseher Was ist denn das für ein Gott?

Matrosa Niemand kann ihn sehen --

30 Toxilus (wirft einen Blick auf Lemniselenis) Aha! Und Du triffst ihn unter der Erde?

Matrosa Noch muss er sich verstecken, denn er ist unser Vater -- der liebe Gott der Sklaven.

(Stille)

35 Toxilus ( $z u$ Matrosa) Was predigt denn dieser neue Gott?

Lemniselenis (sanft) Dass alle Menschen Brüder sind.

Alle Sklaven Alle?

Matrosa Ja. Ob reich, ob arm, ob frei oder unfrei -- alle Menschen sind Kinder unseres Vaters im Himmel. Alle, alle!

40 (Dordalus, der Sklavenhändler aus Pompeji, kommt von links; er schreitet neben einer Sänfte einher, die von TRAEgern getragen wird; in der Sänfte sitzt ein PRAETOR aus Pompeji; einige Liktoren eskortieren das Ganze)

Dordalus ( $z$ u den Traegern) Halt!

Die Traeger (halten)

$\begin{array}{lll}13 & \ulcorner\urcorner] & {[\mathrm{He},]} \\ 15 & \ulcorner\text { Zuwag }\urcorner] & \text { gemeint ist: Zuwaage } \\ 19 & \ulcorner\text { dass }\urcorner] & \text { korrigiert aus: das }\end{array}$


Dordalus (zum Praetor) Wir sind nämlich bereits am Ziel, $\ulcorner$ Euere hochwohlgeborene ${ }^{\urcorner}$Exzellenz!

Praetor Endlich! $\ulcorner$ Doch $\urcorner$ behalt Deine orientalischen Titeln für Dich, ich bin der Praetor von Pompeji und das genügt! (er steigt aus der Sänfte und sieht sich um) $\mathrm{Hm}$. Also dies ist jene Villa --

Dordalus Jawohl, oh Praetor!

Praetor (blickt auf das Dach der Villa) Köstlich, dieses Fries -- gelungene Raumeinteilung.

Dordalus Wirkt wie ein Tempel und doch wohnt nur ein gerissener Gauner drinn --

Praetor (fällt ihm ins Wort) Ich kenne den Herrn!

Dordalus Ich bin zwar kein Antipunist, doch wahr ist, was wahr ist: die Römer haben die Welt, die Punier das Geld!

Praetor Wie abgeschmackt! Schaff mir lieber endlich Deine Hetäre herbei, ich bin ja schon überall wund -- fünf Stunden in einer Sänfte, wer hält denn das aus!

Dordalus Sofort-sofort! ( $z$ u den Sklaven) He, Sklavengesindel! Verfluchtes Pack, wo steckt denn das herrlichste Geschöpf Lemniselenis, das lieblichste Kind von Lemnos? Ich bin Dordalus, Euer Händler!

|| LEMNiselenis Hier bin ich!

Dordalus (zum Praetor) Dort ist sie!

20 Praetor Ich habs gehört, ich bin nicht taub!

Dordalus Sie ist das entzückendste --

PRAETOR (unterbricht ihn schroff) Ich bin nicht blind!

(Stille)

Praetor (betrachtet Lemniselenis; plötzlich) Dreh Dich um!

LEMNISELENIS (lächelt leise; wirft einen flüchtig-schalkhaften Blick auf ToxILUs und dreht sich um)

Dordalus (zum Praetor) No?

(Stille)

Praetor (betrachtet Lemniselenis) Hm. Als Richter verdiene ich pro Prozess normalerweise fünf bis zehn Silberlinge, und wenn ich ein Auge zudrück fünfzig, zwei Augen hundert. Aber heutzutag langt den meisten Leuten leider schon ein Auge, sie lassen sich lieber ein bisserl foltern, es hat halt niemand ein Geld. $\mathrm{Zu}$ meines Vaters Zeiten kosteten ein paar Hetären zwanzig Silberlinge und an einem Prozess verdiente man hundert -- hundert pro Auge! ( $z u$ Lemniselenis) Dreh

35 Dich wieder um!

LEMNISELENIS (folgt und scheint amüsiert zu sein)

Dordalus Zwanzig Silberling für ein paar Hetären -- das muss aber schon hübsch lang her sein!

Praetor (betrachtet noch immer Lemniselenis) Das war noch seinerzeit, wie der Vesuv ausgebrochen ist -- wenn nämlich alles unter der Lava liegt, prozessieren die Leut am liebsten wegen ihrer ${ }^{\ulcorner}$Grundstücksgrenzen. ${ }^{\urcorner}$Also: was soll das Kind kosten?

Dordalus Wenig.

PRAETOR Wenig ist garnichts.

45 || Dordalus Bei mir ist wenig ein bisserl mehr.

1-2 $\ulcorner$ Euere hochwohlgeborene $\rceil]$

3 「Doch $\urcorner]$

$41\lceil$ Grundstücksgrenzen. $\urcorner]$
Eue[r]|re| [Ho]|ho|chwohlgeborene

[Aber] |Doch|

Grundstücksgrenzen $\backslash$./ [--] 
Praetor Wieviel?

Dordalus Nicht viel --

Praetor Also?

Dordalus Sagen wir -- was sagen wir?

5 Praetor Was weiss ich?

Dordalus Wären also, sagen wir, zirka -- für einen Praetor von Pompeji --

Praetor (unterbricht ihn) Wenn ich kaufe, bin ich kein Praetor, sondern ein einfacher freier Bürger!

Dordalus Ojjweh, das hab ich nicht gern!

10 Praetor Gern oder nicht gern, mir wirds jetzt zu dumm! Zeit ist $\ulcorner$ auch $\urcorner$ Geld, also sagen wir: fünfzig!

Dordalus Fünfzig? Fünfzig Silberlinge? Für diese Figur, diese Haar, diese Beine, diese --

Praetor (unterbricht ihn) Also wieviel?!

15 Dordalus Nicht unter dreihundert!

Praetor Dreihundert?! Und das nennst Du wenig?!

Dordalus (frech) Bei mir ist das wenig!

(Stille)

Praetor ( $z u$ Lemniselenis) Dreh Dich nochmal um --

20 LeMniselenis (dreht sich um)

PRAETOR (betrachtet sie wieder) Hm. Eigentlich hab ich mir ja was anderes vorgestellt --

Dordalus Wieso?

PRAeTOR Offen gesagt: mein Fall ist das nicht. Die ist mir zu zart --

DoRDALus (wird nun immer gehässiger) Was Ihr nicht sagt!

PraEtor Die Zarten gehen einem nämlich leicht auf die Nerven und ich brauch etwas fürs Gemüt, ich neige eh zu Melancholie.

\|Dordalus Ihr kauft sie also nicht?

Praetor Nein.

30 Lemniselenis (verbeisst das Lachen) Darf ich mich wieder umdrehen?

Praetor Dreh Dich nur, Kind --

LEMNISELENIS (dreht sich wieder um)

Dordalus (zum Praetor) Und wer zahlt die Sänfte hin und her?

Praetor Du.

DORDALUS Ich?

Praetor Ja.

DORDALUs Und wenn ich mich weiger?

Praetor Dann verurteil ich Dich dazu.

Dordalus Oh Merkur, Gott der Kaufleute, hilf einem ehrlichem Handelsmann!

Praetor Du und ein ehrlicher Handelsmann?! Lästere nicht! Verspricht mir in Pompeji eine überirdische Hetäre zu zeigen, eine reine griechische Aphrodite, ich vertag einen ganzen Prozess, lass mich da mühsam heraustragen und was muss ich sehen?! Ein armseliges Geschöpf mit überall nichts dran -- falsch 「eingehänkte Füss, abstehende Ohren, schiefer Mund, gelbe Haar, wo sie ihre Nase hat, erkennt man überhaupt erst nach längerem Hinschauen -- und schielen tut sie auch!

\footnotetext{
$10\lceil$ auch $\urcorner$ lauch/

43 「eingehänkte $\rceil$ gemeint ist: eingehängte
} 
Toxilus (kann sich nichtmehr beherrschen) Was?! Lemniselenis schielt?!

Praetor ( $z u$ Dordalus) Wer redet da zu mir?

Dordalus Was weiss ich, was gehts mich an!

Toxilus Ich rede, ich! Wie könnt Ihr es wagen, an diesem göttlichem Geschöpfe ein

5 Haar in der Suppe --

LEMNISELENIS (unterbricht ihn erschrocken) Halt, nicht --

Toxilus (unterbricht sie) Nein, das halt ich nicht aus! Ich lass $\|$ das nicht zu! Abstehende Ohren, hat er gesagt! Schiefer Mund, hat er gesagt! Gelbe Haar, falsch $\ulcorner$ eingehänkte ${ }^{\urcorner}$Füss! Oh Götter, nein-nein, jetzt werde ich es aller Welt beweisen, was an Dir dran ist, und zwar überall dran -- denn ich, ich versteh was von $\ulcorner$ der Schönheit der Damenwelt!?

Praetor Ein vermessener Bursche!

$\left\ulcorner\right.$ Toxilus Dordalus, Du alter Hafen, ${ }^{\ulcorner}$schäbiger $\urcorner\ulcorner$Mist voll Gier und Neid $\urcorner$-- hier, hier hast Du sechshundert Silberlinge -- - (er zückt einen Geldbeutel)

Dordalus Sechshundert?!

Toxilus Jawohl, sechshundert! Denn Lemniselenis ist sechstausend wert! Nimm es, räudiger Geldgeier, ich kauf das Mädchen frei!

Dordalus Ein Wohltäter! Gemacht, Herr, gemacht! Aber das Geld müsst Ihr leider behalten, ich hab ja die Dame nur in Kommission $\left\ulcorner\right.$ zum Verkauf ${ }^{\urcorner}-{ }^{-}\ulcorner$aber $\urcorner$wenn Ihr sie freikauft, dann gehört das Geld nicht mir, sondern dem Herrn Präsidenten Thago!

Toxilus (perplex) Wem?

Dordalus Nun, dem Herrn, der hier wohnt. Legt es in seine Kasse!

Toxilus Wohin?!

Dordalus In seine Kasse. Mit Freikaufereien hab ich leider nichts zu tun --

PRAETOR (fällt ihm ins Wort) Aber vielleicht ich, und zwar in meiner Eigenart als Richter! Es will mir nicht recht in den Kram, dass da irgendsoein Bursche für eine Hetäre, die mir missfällt, mirnichts-dirnichts sechshundert Silberlinge -(er fixiert Toxilus) Wer seid Ihr denn? Euer Name?

30 Toxilus (wird etwas unsicher) Toxilus.

Praetor Auch ein Name! Euer Stand?

|| Toxilus Ich bin hier der Oberkammersklave --

Praetor Ahnt ich es doch, dass hier etwas nicht geheuer! Nun, sag mir mal, Toxilus, wieso kann ein unfreier Mann zu「so viel ${ }^{\urcorner}$Geld kommen?

Toxilus Nur durch der Götter Fügung und die Gnade seiner Herrschaft. Mein Herr hats mir geschenkt.

PRAETOR $\ulcorner$ Ich kenne Deinen Herrn $\ulcorner$ persönlich $\urcorner$ ! Der schenkt keinem einen Groschen!

\begin{tabular}{|c|c|c|}
\hline $8-9$ & $\ulcorner$ eingehänkte $\urcorner]$ & gemeint ist: eingehängte \\
\hline $10-11$ & $\ulcorner$ der $\rightarrow$ Damenwelt! $\urcorner]$ & [Frauenschönheit!] |der $\rightarrow$ Damenwelt!| \\
\hline $13-14$ & $\lceil$ ToxiLus $\rightarrow$ Silberlinge -- $]$ & Textentlehnung Plautus, PER ${ }^{17}$ \\
\hline 13 & $\ulcorner$ schäbiger $\urcorner]$ & korrigiert aus: schäbbiger \\
\hline 13 & $\ulcorner$ Mist $\rightarrow$ Neid $\urcorner]$ & Mist[, Geldgeier] |voll $\rightarrow$ Neid $\mid$ \\
\hline 19 & $\left\ulcorner\right.$ zum Verkauf $\left.{ }^{\urcorner}\right]$ & Izum Verkauf/ \\
\hline 19 & $\lceil$ aber $\urcorner]$ & [und] |aber| \\
\hline 35 & $\ulcorner$ so viel $\urcorner]$ & korrigiert aus: soviel \\
\hline 38 & $\ulcorner$ Ich $\rightarrow$ Groschen! $\urcorner]$ & $\begin{array}{l}\text { (1)Wie kann ein Mensch nur so dumm lügen! } \\
\text { (2) \Ich } \rightarrow \text { Groschen!/ }\end{array}$ \\
\hline 38 & $\ulcorner$ persönlich $\rceil]$ & Ipersönlich/ \\
\hline
\end{tabular}


Toxilus Hoher Praetor! Die Wahrheit --

Praetor (unterbricht ihn) Kein Wort mehr, Schluss! Wir werden die Dinge ordentlich klären, tröste Dich! Dein Herr ist verreist?

Toxilus (wird immer unsicherer) Ja, in die Sommerfrische.

5 Praetor Und wann kommt er wieder?

Toxilus Bei meinem Herrn dauert der Sommer $\left\ulcorner\right.$ manchmal ${ }^{\urcorner}$ein halbes Jahr. Er ist nach Kreta --

PrAetor (fällt ihm ins Wort) Ein halbes Jahr? Dann werden wir es also erst im Winter erfahren, ob Du im Frühling die Wahrheit gesprochen hast. Bis dahin wirst Du mich wohl nach Pompeji begleiten müssen -- (zu seinen LiKTOREN) Verhaftet ihn!

Lemniselenis Nein! Oh hoher Praetor, er sagt die Wahrheit, glaubet mir, auch wenn Ihr mich nicht für schön findet! Ich selber war ja dabei, wie der Herr ihm das Geld gab, ich schwör Euch jeden Eid, der Euch heilig ist! Aber wenn Ihr ihn jetzt trotzdem einkerkert, dann kerkert auch mich ein -- auch mich! (sie weint)

Praetor (lächelt) Ach, ist Amor mit im Spiele? (leise zu Lemniselenis, damit es Dordalus nicht hört) Liebes Kind, im Vertrauen: ich finde Dich sehr schön -und ich hab Dich zu-\|vor nur deshalb für hässlich $\ulcorner$ befunden $\urcorner$, weil Du mir zu teuer warst. Verzeihe einem armen Richter -- $\ulcorner$ jetzt lächelst Du wieder! Ich bin auch kein Unmensch und würde Dir gerne Deinen Toxilus gönnen, aber Recht muss Recht bleiben, sonst hört sich unsere menschliche Gesellschaft auf und alles geht drunter und drüber --

B AGNiO (kommt mit seinem Prügel rasch hinter der Villa hervor und ruft) Toxilus! Toxilus! Das Schiff ist untergegangen, das ganze Schiff!

Matrosa Was für ein Schiff, um Gottes Willen?!

B AGNio (hocherfreut) Das Schiff Euerer Herrschaft!

Toxilus Was redest Du da?!

Alle Sklaven Untergegangen?!

B AGNIO Und ob! Ich lag heut früh auf meinem Felsen, von dem man das halbe Meer überschaut -- $\ulcorner$ von $\urcorner$ dort verfolgte ich $\ulcorner$ Euere Fregatte $\urcorner$ ! Plötzlich, aus heiterstem Himmel heraus, $\ulcorner$ ballt $\urcorner$ sich $\ulcorner$ da $\urcorner$ ein Gewitter zusammen, ein Blitz und bumm! $\ulcorner$ der Kahn ist ${ }^{\urcorner}$futsch! Habedieehre mit Mann und Maus! Euere Herrschaft ist nichtmehr! Alles ersoffen, alles!

AufseHER Ersoffen?!

B Agnio (erblickt erst jetzt den Praetor und erschrickt) Huj, der Praetor von Pompeji!

Praetor Wer bist Du?

B AGNIO Ihr kennt mich nicht?

Praetor Keine Ahnung!
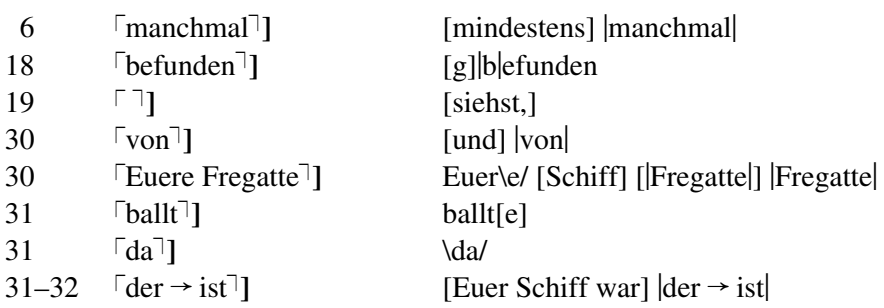
B AGNio Sehr angenehm! ( $z u$ ToxiLus) Er hat mich zwar schon $\left\ulcorner\right.$ ixmal ${ }^{\urcorner}$verdonnert, aber wahrscheinlich sah er mir dabei nie in die blauen Augen -- (er grinst und will seine Hand auf ToxiLus Schulter legen)

Toxilus Rühr mich nicht an, ich bin verhaftet!

5 B AGNio (erschrickt sehr) Verhaftet?! Bimbambum!

Praetor Jetzt nichtmehr. Toxilus, Du bist frei!

LEMNISELENIS (hochbeglückt) Frei?!

|| Praetor Du sagst es -- denn wo kein Kläger, kein Angeklagter, und die Beweise seiner Schuld liegen am Meeresgrund -- (er blickt zum Himmel empor)

10 Lemniselenis Fein, fein! (sie umarmt sich mit Toxilus)

Alle SkLaVen (sehen beglückt aus)

PRAETOR (blickt noch immer empor)

Schrecklich ist manchmal das Walten der Götter

Rätselhaft ihr Urteil

Unfassbar für einen irdischen Richter.

Oh Jupiter!

Du erschlägst das Recht mit Deinem Blitz

Und lässt das Unrecht triumphieren --

$\ulcorner$ Sagt, $\urcorner$ Götter, was habt Ihr vor mit unserer Welt?!

20 (Stille)

PRAETOR (wendet sich langsam lächelnd an seine LiKTOREN) Kommet! Wir warten umsonst auf Antwort -- (ab nach links mit Dordalus und den LikTOREN)

Lemniselenis Freude, doppelte, dreifache Freude!

Alle Sklaven Freude, Freude, Freude!

25 (Musik erklingt)

$\ulcorner$ Toxilus Jetzt lasst uns singen -- die Herrschaft ist hin!

LEMNISELENIS Singen und tanzen!

BAGNIO Und saufen!

Toxilus (zu den SkLAVEn) Hinein mit Euch, öffnet alle Schränke und Truhen! Ziehet die Fetzen der Herrschaft an!

B AGNIO Und was Ihr nicht anziehen könnt, das zerfetzt in Stücke!

Toxilus Wein her! Alle Fässer, alle Flaschen!

BAGNio Zerschlagt $\ulcorner$ das Glas!

Toxilus Scherben bringen Glück! Toxilus und Lemniselenis laden Euch ein zu ihrem Ball! Und wenns nur ein paar $\|$ Stunden $\ulcorner$ dauern sollte $\urcorner$-- wagt es doch mal, frei zu sein! Wagt es!

B AGNIO Zertrümmert alles! Alles-alles!

Alle SkLAVEN (befolgen mit Jubel die Ratschläge, kommen aus der Villa in den Kleidern der Herrschaft mit Wein und Braten und Torten; sie singen)

Es öffnet sich heute des Sklavenzwingers Tor

Da kugelen die Sklavelein ganz haufenweis hervor!

Die Männlein und die Weibelein

\footnotetext{
$\left.1\left\lceil{ }^{-i x m a l}\right\urcorner\right]$

$19\lceil$ Sagt, $\urcorner]$

26-36 「ToxiLus $\rightarrow$ es! ]

$33\lceil$ das Glas! $\rceil]$

$35\lceil$ dauern sollte $\rceil]$
}

\author{
gemeint ist: $\mathrm{x}$-mal \\ Sagt $\backslash, /$ \\ Textentlehnung Plautus, PER ${ }^{18}$ \\ [die Gläser!] [|\{Wein\}|] |das Glas!| \\ dauer[t]|n| Isollte/
}


Sie wollen alle Freie sein

Sie kugelen, sie kugelen

Bald hin und bald her

$\mathrm{Zu}$ unterst, zu überst

Das freut sie umso mehr!

Lemniselenis Auf dem Meer ist $\ulcorner$ es $\urcorner$ so still, wie die ewig Ruh

Kein Orkan drückt der Matrosen Schuh

Wölklein, die siehst schon von weitem $\ulcorner$ wehen $\urcorner$

Heut wirds auch ohne Ruder gehen --

10

Ihr Sklaven, wir wollen nach Kreta fahren

Kreta ist jenseits aller Gesellschaftsgefahren

In Kreta, dort ist der Wein so süss

Dort ist das zweite Paradies --

15

Wir segeln, wir segeln in die Sommerfrisch

Lustig im Wasser schwimmt mit uns der Fisch

Der uns zur Zeit verspeist gerad

Tief drunten im Meeresgrab --

20 ( $z$ u den Sklaven) Nun klatscht!

Alle (ausser MAtrosA, die sich $\ulcorner$ während des ganzen Balles $\urcorner$ abseits hält, applaudieren)

AUFSEHER (bereits etwas betrunken)

Denn auf den Meeren, da wohnt die Freiheit

$25 \quad$ Ja auf den Meeren ist es schön

Allwo die hohen Herren, samt ihrer Freiheit

Können untergehen!

Toxilus (zum Aufsener) Geistreich! Sehr witzig!

Aufseher (gekränkt) Wenn Du mir schon die Peitsche nimmst, dann klatsch wenigstens, wenn ich sing! Nicht schön von Dir!

B AGNio (klopft mit seinem Prügel auf ToxiLus Schulter)

Fuchs Du hast die Gans gestohlen

Gib sie wieder her

Sonst wird Dich der Praetor holen

35

Mit seinem Paragraphenheer --

Aufseher ( $z u$ LEMNiselenis)

Prosit ex!

Trink aus Du kleine Hex!

(Allgemeiner Tanz)

40 Alle Ojje, ojje, wie rührt mich das

Wie rührt mich das, wie rührt mich das

Viel zu lang habt Ihr gelebt

Das $\ulcorner$ Kaputtsein $\urcorner$ kam zu spät!

$\begin{array}{rll}6 & \ulcorner\text { es }\urcorner] & \text { eingefügt } \\ 8 & \ulcorner\text { wehen }\urcorner] & \text { weh[n]|en| } \\ 21 & \ulcorner\text { während } \rightarrow \text { Balles }\urcorner] & \backslash \text { während } \rightarrow \text { Balles/ } \\ 43 & \ulcorner\text { Kaputtsein }\urcorner] & \text { korrigiert aus: Kaputsein }\end{array}$


Lemniselenis Der Blitz schlug ein --

Hurrah, wie fein!

Er schlug sie alle tot

Alle, alle tot!

$5 \quad\ulcorner\urcorner$ Der Blitz schlug ein --

$\left\ulcorner\operatorname{ALLE}^{\urcorner}\right.$Hurrah, wie fein!

Er schlug sie alle tot

Alle, alle tot!

Ojje, ojje, der Kopf ist ab

10 Der Kopf ist ab, der Kopf ist ab

Wie rührt mich das, wie rührt mich das

| Wie rührt, wie rührt mich das!

LeMniselenis (tanzt mit Toxilus)

Ach, wie ist es möglich dann

Dass ich Dich hassen kann!

Hasse Dich so schrecklich lieb

Du meiner Freiheit liebster Dieb!

Aufseher Hieb um Hieb!

Dick und dünn!

Paegnium Zwirn, Zwirn, Zwirn!

BAGNIO Zwirn ist kein Strick

Dünn oder dick!

(er macht die Geste des $\ulcorner$ Gehänktwerdens $\urcorner$ )

ToxiLus Dick oder dünn

Strick ist kein Zwürn!

(er macht die Geste des Einfädelns)

B AGNio und Toxilus Lasst uns entwürrn!

Toxilus Zwirn, Zwirn, Zwirn

$30 \quad$ Ein Kopf ist noch kein Hirn

Ein Hut ist noch kein Kopf

Ein Hals ist noch kein Kropf

Gedacht, getan, etcetera

Für unsereins sind nur wir da!

${ }_{35}\ulcorner$ Alle Gedacht, getan, etcetera

Für unsereins sind nur wir da!

LeMniselenis (tanzt mit Toxilus einen Walzer)

Hunde, die bellen, beissen nicht

Sklaven, die klagen, die morden nicht

Herren, die gut sind, die gibt es nicht

Die gibt es nicht, die gibt es nicht!

Alle (tanzen Walzer, summen die Melodie und singen nur die letzte Zeile)

Die gibt es nicht, die gibt es nicht!

$\begin{array}{lll}5 & \ulcorner\urcorner] & {[\text { ALLE] }} \\ 6 & \ulcorner\text { ALLE }\urcorner] & \text { ALLE/ } \\ 23 & \ulcorner\text { Gehänktwerdens }\urcorner] & \text { gemeint ist: Gehängtwerdens } \\ 35-36 & \ulcorner\text { ALLE } \rightarrow \text { da! }\urcorner] & \text { AALLE } \rightarrow \text { da!/ }\end{array}$


||PAegnium (hatte sich einen Helm des Gloriosus aufgesetzt und betrachtet sich in einem seiner Schilde)

Putz den Schild

Putz, putz, putz!

5

Nur kein Trutz

Trutz, Trutz, Trutz!

Wo bin ich, wo bin ich?

Seh mich nicht, blend ich Dich --

(er schreit plötzlich) Wo seid Ihr jetzt, stolzer Gloriosus?! Erhabener Tepp, siehst

Du Dich jetzt?! Wer putzt dort Deinen Schild, wer?! Kämpfst mit tausend Haifischen, Polypen und Seeschlangen und hast sie alle besiegt, was?!

Alle (lachen)

AufseHER (nun total betrunken)

Ich gerbt es gern in alle Häute ein

Ich ätzt es gern in jedes Herrn Bein

Dein ist mein Schmerz

Dein ist mein Schmerz

Und soll er ewig, ewig Dein bleiben --

(er fällt um)

20 Alle (lachen)

PAEgnium (plötzlich)

Zwirn, Zwirn, Zwirn!

Toxilus Ein Kopf ist noch kein Hirn!

(Wieder allgemeiner Tanz)

BAGNIO Gedacht, getan, etcetera

Alle Für unsereins sind nur wir da!

Lemniselenis Flieg, Delphin, flieg --

Ein Krieg ist noch kein Sieg

30 - Ein Sieg ist noch kein Frieden

Wo ist mein Herr geblieben?

Der Blitz schlug ein --

Alle Hurrah, wie fein!

Er schlug sie alle tot

Alle, alle tot!

B AGNiO (näherte sich Matrosa)

Du Prügel in meiner Linken

Was soll Dein heiteres Blinken?

Siehst mich so freundlich an

Morgen kommst wieder Du daran --

Matrosa (stösst B AGNIO von sich)

(Es $\ulcorner\text { donnert und die Musik spielt plötzlich ganz leise })^{\urcorner}$

Alle (hören auf zu tanzen und horchen auf; sie blicken $\ulcorner$ nach dem $\urcorner$ Himmel und bemerken es erst jetzt, dass er sich bezogen hat; die Sonne verschwindet)

$\begin{array}{lll}29 & \ulcorner\urcorner] & {[\text { Ein Sieg ist noch kein Frieden }]} \\ 43 & \ulcorner\text { donnert } \rightarrow \text { leise })]] & \text { donnert }[)] \mid \text { und die Musik }[\text { verstummt })] \mid \text { spielt plö } \backslash \text { t/zlich ganz leise }) \| \\ 44 & \ulcorner\text { nach dem }\urcorner] & {[\text { auf }] \mid \text { nach } \mid \text { de }[n]|m|}\end{array}$


LEMNiSELENis (bange) Was war das?

Matrosa Es donnert.

Bagnio Das kommt vom Meer --

( $\ulcorner$ Pause $\urcorner)$

5 Toxilus Es kommt nicht her.

Matrosa Abwarten!

Toxilus Es verzieht sich --

(Es donnert wieder)

B AGNIO (zuckt etwas zusammen) Ich glaub, es kommt --

10 Toxilus Aber nichts kommt! Das geht an uns vorbei und Schluss! Weiter!

(Wieder $\left\ulcorner\right.$ laute ${ }^{\urcorner}$Musik und allgemeiner Tanz)

Alle Ojje, ojje, der Kopf ist ab

Der Kopf ist ab, der Kopf ist ab

\| Viel zu lang habt Ihr gelebt

ÖLA 3/W 109

Das $\ulcorner$ Kaputtsein $\urcorner$ kam zu spät!

LeMniselenis Der Blitz schlug ein --

Alle Hurrah, wie fein!

Er schlug sie alle tot

Alle, alle tot!

20 (Heftiger Blitz und Donner, die Musik verstummt, Sturmstoss -- rasch wird es finster)

ALLE (schrecken sehr zusammen)

BAGNio Es regnet!

Alle Es giesst, es giesst! Flieht, flieht! (sie fliehen in die Villa, nur ToxiLus, LemniSELENIS und MATROSA bleiben unter dem Vorbau bei den Säulen stehen)

25 (Zweiter Sturmstoss)

BAGNio Na servus! Also ich vertrag alles, nur kein Wetter! Da krieg ich Nerven! (rasch ab in die Villa)

(Wolkenbruch)

ToxiLus `Ein Wolkenbruch. Zu dumm!

30 Lemniselenis Einmal wär man in seinem Element gewesen --

(Stille)

Matrosa Habt Ihr keine Angst?

Toxilus Wir? Warum?

Matrosa Vor dem Blitz.

35 Toxilus Nein. Hin ist hin!

Matrosa Und was kommt dann?

Toxilus Frag nicht so $\ulcorner$ dumm - $\urcorner$

(Es blitzt stark, ohne zu donnern)

LEMNISELENIS (zuckt sehr zusammen) Oh! (sie verbirgt das Antlitz an der Brust ihres

40 Toxilus)

ToxiLus Fürchte Dich nicht --

|| LeMniselenis Wenn der mich trifft!

Toxilus (streichelt sie) Er trifft uns nicht.

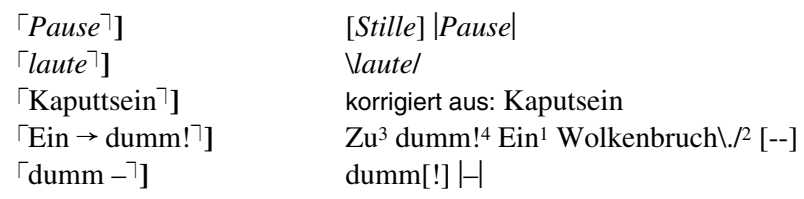


Matrosa Wer hat Dir das verraten?

Toxilus Frag nicht so dumm!

(Dritter Sturmstoss -- dann wieder Stille)

Matrosa (singt leise und spöttisch)

5

Zwirn, Zwirn, Zwirn

Ein Kopf ist noch kein Hirn

Ein Hut ist noch kein Kopf

Ein Hals ist noch kein Kropf

Gedacht, getan, etcetera

10

Für unsereins sind nur wir da --

Toxilus Mir scheint, es freut Dich, dass unser Ball verregnet?

Matrosa Ja.

Toxilus Wie freundlich! Jetzt glaub ichs bald, Du würdest auch singen, wenn uns

Beide da der Blitz träf --

15 Matrosa (fällt ihm ins Wort) Ihr habt es verdient, dass er Euch trifft -- Euch alle!

Toxilus Hoppla!

Matrosa Du tust $\ulcorner$ ja $\urcorner$, als hättest Du Deinen Herrn erschlagen -- aber den Blitz sandte ein $\ulcorner$ Anderer! $\urcorner$ Einer, der unsere Leiden sah -- doch wird $\mathrm{er}^{\ulcorner}{ }^{\ulcorner}$uns $\ulcorner$ebenso $\urcorner$erschlagen, wenn $\ulcorner$ wir in $\urcorner$ unserem Feinde nicht $\ulcorner$ auch $\urcorner$ den Bruder erkennen --

20 Toxilus (etwas $\ulcorner$ ironisch $\urcorner$ ) Aha! Wieder $\left\ulcorner\right.$ dieser ${ }^{\urcorner}$neue Gott --

Matrosa Immer und ewig.

(Stille)

Lemniselenis (plötzlich zu Matrosa) Ich möcht gern mal mit. Zu Deinem Gott.

Aber ich hab Angst.

25 Matrosa Warum?

LEMNISELENIS Weil man so tief hinunter muss unter die Erde.

|| Matrosa (lächelt) Halb so schlimm --

LEMNISELENIS Und finster ists drunten!

Matrosa Halb so finster, wie hier! Es brennen $\left.{ }^{\ulcorner}\right\urcorner \operatorname{immer}^{\ulcorner\urcorner}$viele Kerzen.

Lemniselenis (wie ein Kind) Ach fein! Die hab ich gern! ( $z u$ Toxilus) Du kommst doch auch mit?

Toxilus Warum?

Matrosa Du wirst es nicht bereuen.

Toxilus (horcht auf)

35 Matrosa Es ist eine andere Welt.

(Stille)

LEMNISELENIS Ich bin schon neugierig.

Matrosa Ja es ist herrlich bei uns.

$\ulcorner$ LEM Was soll man sich denn da anziehen?

\begin{tabular}{|c|c|c|}
\hline 17 & $\ulcorner\mathrm{ja}\urcorner]$ & $\mid \mathrm{ja} /$ \\
\hline 18 & $\ulcorner$ Anderer! $\rceil]$ & [a]|A|nderer $\mid / /$ [Herr.] \\
\hline 18 & \ulcorner\urcorner$]$ & [auch] \\
\hline 18 & $\lceil$ ebenso $\rceil]$ & lebenso/ \\
\hline 19 & $\ulcorner$ wir in $\urcorner$ & korrigiert aus: wir in \\
\hline 19 & $\lceil$ auch $\rceil]$ & lauch/ \\
\hline 20 & $\lceil$ ironisch $]$ & $\operatorname{ir}[n] \mid$ on $\mid$ isch \\
\hline 20 & $\ulcorner$ dieser $\urcorner]$ & diese $\backslash r /$ \\
\hline 29 & \ulcorner\urcorner$]$ & [ja] \\
\hline 29 & \ulcorner\urcorner$]$ & [so] \\
\hline $39-372,2$ & $\ulcorner$ LEM $\rightarrow$ Glas -$\urcorner]$ & LEM $\rightarrow$ Glas $-/$ \\
\hline
\end{tabular}


Matrosa Nicht zu $\ulcorner$ auffällig $\urcorner$ geschmückt -

LEM (lächelt) Ist eh alles nur Glas -

$\left\ulcorner\right.$ Matrosa ${ }^{\urcorner}$Und dann singen wir.

Toxilus (lächelt, fast traurig) Schöner wie wir zuvor?

5 Matrosa (heiter) Das will ich meinen!

(Stille)

Lemniselenis ( $z u$ Toxilus) Nicht traurig sein --

(Es wird langsam wieder heller)

MATRosa (blickt empor) Es geht vorbei --

10 Lemniselenis (blickt empor) Ja.

ToxiLus (blickt auch empor, sagt aber nichts)

Die SkLaVen (in der Villa -- fangen wieder an zu singen)

Der Blitz schlug ein --

Hurrah, wie fein!

15

Er schlug sie alle tot

Alle, alle tot!

Toxilus (ruft plötzlich in die Villa hinein) Ruhe! Ruhe!

(Stille -- ein Sonnenstrahl bricht durch)

LEMNiselenis (umarmt Toxilus)

(Vorhang)

ENDE

\begin{tabular}{lll}
\hline 1 & $\ulcorner$ auffällig $\urcorner]$ & [sch] lauffällig| \\
3 & $\ulcorner$ MATROSA $\urcorner]$ & eingefügt
\end{tabular}

